\title{
Optimal Decision Making in Electrical Systems Using an Asset Risk Management Framework
}

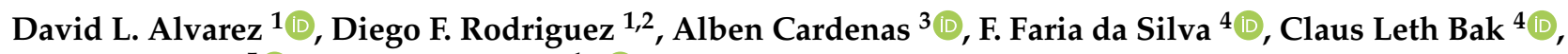 \\ Rodolfo García $^{5}$ (D) and Sergio Rivera ${ }^{1, *(D)}$ \\ 1 Department of Electric and Electronic Engineering, Universidad Nacional de Colombia, \\ Bogotá 111321, Colombia; dlalvareza@unal.edu.co (D.L.A.); dfrodriguezmed@unal.edu.co (D.F.R.) \\ 2 GERS USA, Weston, FL 33331, USA \\ 3 Department of Electrical and Computer Engineering, Université du Québec à Trois-Rivières, \\ Trois-Rivières, QC 3592, Canada; alben.cardenasgonzalez@uqtr.ca \\ 4 Department of Energy Technology, Aalborg University, 9100 Aalborg, Denmark; ffs@et.aau.dk (F.F.d.S.); \\ clb@et.aau.dk (C.L.B.) \\ 5 Deparment of Operation \& Maintenance, Enel-Codensa, Bogotá 11010, Colombia; rodolfo.garcia@enel.com \\ * Correspondence: srriverar@unal.edu.co
}

\section{check for}

updates

Citation: Alvarez, D.L.;

Rodriguez, D.F.; Cardenas, A.;

da Silva, F.F.; L. Bak, C.; García S, R.;

Rivera, S. Optimal Decision Making

in Electrical Systems Using an Asset

Risk Management Framework.

Energies 2021, 14, 4987.

https://doi.org/10.3390/

en14164987

Academic Editors: Olivier Bahn and Azadeh Maroufmashat

Received: 28 June 2021

Accepted: 9 August 2021

Published: 13 August 2021

Publisher's Note: MDPI stays neutral with regard to jurisdictional claims in published maps and institutional affiliations.

Copyright: (C) 2021 by the authors Licensee MDPI, Basel, Switzerland. This article is an open access article distributed under the terms and conditions of the Creative Commons Attribution (CC BY) license (https:/ / creativecommons.org/licenses/by/ $4.0 /)$.

\begin{abstract}
In this paper, a methodology for optimal decision making for electrical systems is addressed. This methodology seeks to identify and to prioritize the replacement and maintenance of a power asset fleet optimizing the return of investment. It fulfills this objective by considering the risk index, the replacement and maintenance costs, and the company revenue. The risk index is estimated and predicted for each asset using both its condition records and by evaluating the consequence of its failure. The condition is quantified as the probability of failure of the asset, and the consequence is determined by the impact of the asset failure on the whole system. Failure probability is estimated using the health index as scoring of asset condition. The consequence is evaluated considering a failure impact on the objectives of reliability (energy not supplied -ENS), environment, legality, and finance using Monte Carlo simulations for an assumed period of planning. Finally, the methodology was implemented in an open-source library called PywerAPM for assessing optimal decisions, where the proposed mathematical optimization problem is solved. As a benchmark, the power transformer fleet of the New England IEEE 39 Bus System was used. Condition records were provided by a local utility to compute the health index of each transformer. Subsequently, a Monte Carlo contingency simulation was performed to estimate the energy not supplied for a period of analysis of 10 years. As a result, the fleet is ranked according to risk index, and the optimal replacement and maintenance are estimated for the entire fleet.
\end{abstract}

Keywords: asset management; decision making; health index; Monte Carlo simulations; risk index

\section{Introduction}

Utilities are facing challenges in their operation, maintenance, and planning. This is a consequence of fulfilling regulations, seeking improvements in both profitability and strategic objectives. Regulation demands more sustainability, reliability, quality, and security of the system with a constant assessment of a utility's revenue. In order to accomplish higher regulations and to meet the company goals, decisions must be optimized [1]. Most of these decisions are related to intensive investments on physical assets. These investments commonly include the replacement, refurbishing, or monitoring of aging assets. Investments are subject to budgetary constraints, the lack of qualified staff able to do the replacement, long waiting times for manufacturing some power assets, etc. These challenges are summarized in the CIGRE TB 787 [2], where it is stated that the assessment of power systems assets needs to increase its sophistication and rigor because they are in a perfect storm. Therefore, decisions must be made considering optimal cost effectiveness. For instance, 
in [3], a conceptual framework is shown for linking physical asset management practices and their performance implications. The framework was implanted in a survey measuring the next AM variables: strategy and plan, life-cycle, asset information, asset review, and, finally, risk assessment. A similar work was presented recently in [4] seeking to establish the relationship between asset management and business performance.

In order to improve decision making, the decisions must be supported and aligned with the utility objectives. One way to support the decisions is by using an asset management strategy [5]. With such a strategy, both asset condition and criticality can be employed to support optimal decisions using the risk index. However, issues related to the index estimation of electric assets must be faced as a consequence of a lack of consensus and international standards [6].

In spite of these asset management challenges, improvements in asset maintenance and replacement strategies using data analytics are reported in the literature. For instance, algorithms using big data to estimate optimal maintenance and replacement of distribution transformers and poles by predicting the aging of assets are addressed in [7]. However, these algorithms are focused on preventive maintenance due to their simple implementation at the distribution level.

In [8], RADPOW (reliability assessment of electrical distribution systems) code is used to develop a method assessing, in a cost-benefit way, the impact of a maintenance strategy on the reliability of power distribution systems. Similarly in [9], a transformer maintenance assessment method is developed using a semi-Markov state diagram. In the aforementioned methods, both the rate of failure and their impact are provided by statistics over a whole network. Therefore, asset condition records are not considered, implying that a forecast of the future condition is not contemplated. In [10], a model for optimal decision making considering reliability and cost is addressed for power transformers. The optimal decision making is focused on evaluating the maintenance strategy by which the maximum reward is obtained. However, in the cost function, the energy not supplied due to a transformer failure is assumed to be constant. In [11], a procedure to realize a replacement plan considering reliability and cost is addressed. The decision making considers the impact on the whole system. In this tool, the asset age is represented by a bathtub curve considering its condition and the reliability $\mathrm{N}-2$ criteria.

A model of composite power system assets is addressed in [12]. This model seeks to identify critical components of a power system. The critical analysis is performed using the costs of system contingencies with a state enumeration instead of a Monte Carlo simulation. The advantage of using state enumeration is that the probability of failure of the assets can be analyzed independently of their failure consequence. In this case, the consequence is the cost of the expected energy not supplied. Nevertheless, load forecasting and condition assessment are not considered.

OFGEM, Great Britain's independent energy regulator, published a common framework [13] for Distribution Network Operators, where the methodology for risk assessment is addressed, including the estimation of health index, probability of failure, and monetization of criticality throughout time. However, in this framework, methodologies for supporting optimal decision making and the use of historical condition records for forecasting asset condition are not addressed, and the major of the variables are estimated using the operation conditions of Great Britain. A global asset management approach has been introduced in the project PRIAD [14] by Hydro-Quebec, proposed to develop an asset management decision support tool in order to ensure utilities' sustainability and performance [15]. This plan considers developing modules for data warehouses, asset behavior, reliability, transmission system simulator, risk, and optimization, while considering the decision-making process in a holistic way. These modules are currently under development and just consider maintenance strategies. Additionally, the methods to optimize the maintenance strategy are currently under investigation. Finally, in [2], approximations performed by different utilities are presented, where the importance of risk assessment using estimations of probability of failure and critically can be concluded. 
However, the lack of both consensus for the definition of asset index and decision-making optimization methodologies can be evidenced.

In [16], the CIGRE defined the modern asset management in power networks as the use of asset health and asset criticality to prioritize the replacement or maintenance of an asset fleet. The health index could be linked with the probability of failure in order to estimate the risk index. In line with the CIGRE's definition and in order to support decision making in electrical systems in a common asset management framework, the present paper proposes a methodology to estimate in a novel way the optimal decision making for both replacement and maintenance. This methodology assesses and predicts the condition, reliability, and risk of an electrical asset fleet considering individual assets as a part of a whole system. The condition is scored using diagnostics records, the reliability is assessed by Monte Carlo contingency simulations during an assumed period of planning, and the risk is computed as the impact of the contingency by the probability of failure. The objective function is formulated to obtain the highest return of investments (ROI) considering incomes, risk monetized, and cost of decisions. This assessment can be used as an input for cost-effective decision making in maintenance and replacement of physical assets, as well as for benchmarking. Finally, this methodology was implemented in an open library called PywerAPM.

According to the literature review, the main contribution of this paper is considering in a novel way the whole optimization problem with the following methodology features:

- Criticality assessment by Monte Carlo simulations considering both load growth and profile;

- Forecasting of asset management index using diagnostic records;

- Monetization of strategic objectives such as financial, environmental, legal, and reliability;

- Comparison between "do nothing", replacement, or maintenance strategies for an asset

fleet considering the optimal ROI modeling the risk variation in time as TOTEX outcomes;

- A mathematical formulation in order to reduce the computational effort to estimate optimal maintenance strategies and replacement time is presented.

Figure 1 summarizes the framework proposed to estimate the optimal return of investment of a power asset fleet from replacement or maintenance.

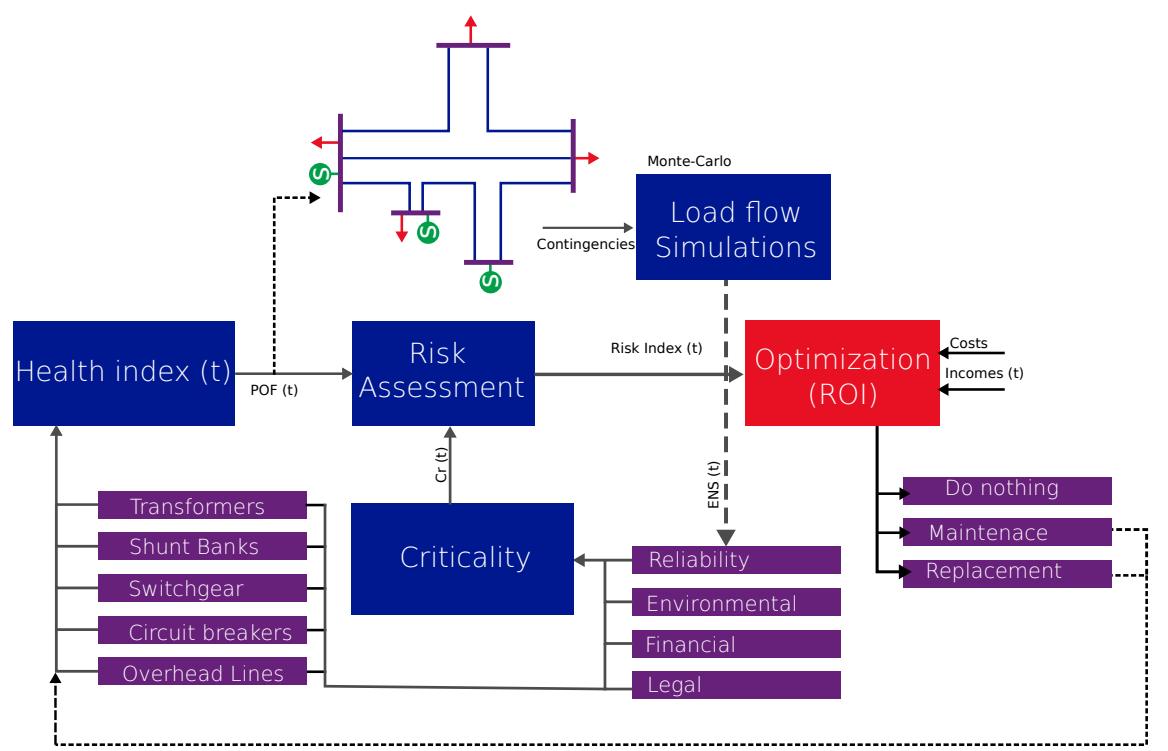

Figure 1. Proposed framework for optimal decision making of a power asset fleet using risk assessment.

The remainder of this paper is organized as follows: Section 2 presents the approximation used to estimate the risk index of a fleet of assets using their condition and criticality. Section 3 describes the formulation to compute the optimal replacement and maintenance frequency of an asset. Section 4 presents the results of the assessment of the entire power 
transformer fleet belonging to the IEEE 39 Bus System. Finally, Section 5 closes with conclusions.

\section{Asset Management Framework}

In this section, the risk index (RI) assessment of an asset fleet is addressed. The index is estimated using the probability of failure of an asset and the assumed impact of this failure on the whole network. This impact is defined as the criticality. The conceptual model of the asset management framework is presented in [17].

\subsection{Asset Condition Using Health Index (HI)}

To score the condition of a physical asset, the health index (HI) is commonly used $[18,19]$. $\mathrm{HI}$ can be computed using a weight function as follows:

$$
H I(t)=\frac{\sum_{n=1}^{N} \beta_{n}\left(S(t)_{n} \cdot w_{n}\right)}{\sum_{n=1}^{N} \beta_{n} w_{n}},
$$

where $t$ is the evaluation time, $S(t)$ is the score of a specific condition, which is commonly normalized in the range [0-1], 0 being the best condition and 1 the worst condition; $w$ is the weight given to the condition; $\beta$ is a binary coefficient which represents the data availability; and $N$ is the number of conditions scored. Health index at the instant $t(H I(t))$, as the score $S(t)$, can take values in the range [0-1], 0 being the best condition and 1 the worst condition.

\subsection{Reliability Assessment}

With the condition scored by the HI, the failure rate of an asset $(\lambda)$ [20] can be estimated as follows:

$$
\lambda(t)=a \cdot e^{b \cdot H I(t)}+c,
$$

where $a, b, c$ are constants to fit using both historical failure rates and condition reports. In order to formulate the optimization problem addressed in Section 3, it is proposed to fit the following logistic function using Equation (2):

$$
\lambda(t)=\frac{L}{1+e^{-k\left(t-t_{0}\right)}}+\lambda_{0}
$$

where $L, k, t_{0}$ are the parameters of the logistic function to be fitted. In other words, with the purpose of fitting the failure rate to a logistic function using the health index forecast Equation (1), the points to fit Equation (3) are computed using Equation (2), which are estimated using the HI. Hence, the integral of the cumulative failure rate is given by

$$
\int_{t_{\text {beg }}}^{t_{\text {end }}} \lambda(t) d t=\int_{t_{\text {beg }}}^{t_{\text {end }}}\left(\frac{L}{1+e^{-k\left(t-t_{0}\right)}}+\lambda_{0}\right) d t
$$

With the estimation of the failure rate, the reliability $(R(t))$ of an asset during its life can be computed by

$$
R(t)=e^{-\int_{t_{\text {beg }}}^{t_{\text {end }}} \lambda(t) d t},
$$

where $t_{\text {beg }}$ and $t_{\text {end }}$ are the current time and the end time of the assessed period, respectively. Finally, the probability of failure $(P O F(t))$ can be estimated using the reliability as follows:

$$
\operatorname{POF}(t)=1-R(t)
$$




\subsection{Risk Index}

The risk index $(R I)$ of an asset is defined as the probability of failure $(P O F)$ times the criticality $(\mathrm{Cr})$ or impact of the failure on the entire system as follows:

$$
R I(t)=C r(t) \cdot \operatorname{POF}(t)
$$

However, the POF and the $\mathrm{Cr}$ are time varying. As the asset ages, operating conditions can influence its health. To illustrate this, the condition degradation of a power transformer can be accelerated due to high temperatures, electromagnetic transients, or an incipient internal failure which influences the oil and insulation quality. On the other hand, the criticality can increase throughout time as a consequence of system growth and therefore with the energy not supplied (ENS) during a contingency. Hence, the criticality depends on both the duration of the failure rate and the operating conditions during the failure. The duration of failure can be assessed with the mean time to repair (MTTR), and the operating conditions can be assessed using reliability analysis, such as N-POF(N) (probabilistic assessment) instead of $N-1$, with load forecast models during an assumed period of planning.

In order to assess the decision making using the risk index, it is suggested to measure the criticality as a monetary consequence [16] of the asset failure. This consequence can be evaluated considering different objectives, such as safety, finance, environment, reliability, etc. The risk monetization facilitates the costs/benefits assessment of different decisions and therefore the determination of optimal expenditure strategy on assets.

\section{Proposed Risk Assessment Procedure}

The proposed algorithm to estimate optimal decision making considering the risk is addressed.

\subsection{Risk Index Forecasting}

The algorithm proposed to estimate the risk index is shown in Figure 2. The inputs of the procedure are the net name, the asset portfolio, the starting date of assessment, the number of Monte Carlo trials, and the number of hours of the assumed period of planning. The algorithm is divided into three main stages, as suggested in [8]. In the first stage, the health index of the entire fleet is assessed. Subsequently, in the second stage, to assess the reliability of the system and to estimate the expected energy not supplied, a Monte Carlo simulation is performed during the assumed period of planning. Such a simulation models the probability of operating the system under security margins when an asset fails. Security margins are determined by the loading limits of transformers and lines and by bus voltages; for this, redundancy is commonly used at the transmission level. Finally, in the third stage, the risk assessment for each asset is performed using the results of the Monte Carlo simulation. To simplify the risk assessment, an optimal secure power flow rescheduling considering losses and cost is not taken into account. 


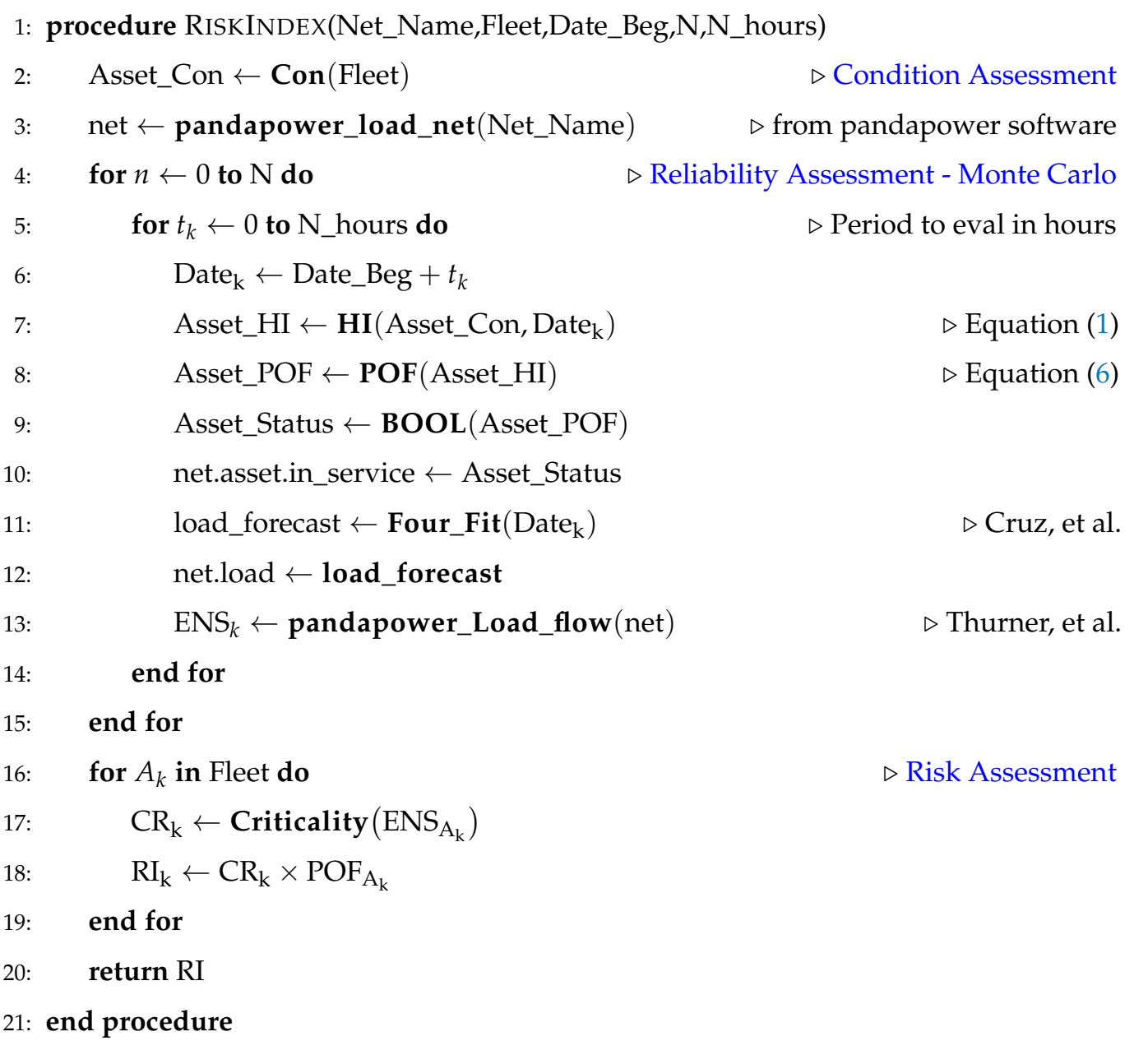

Figure 2. Proposed pseude-algorithm for risk assessment of an electric asset fleet.

For condition assessment, the scoring normalization of the health index is carried out using a linear interpolation for each condition assessed. Subsequently, to predict the health index, a function fit for each condition is performed as follows:

$$
S(t)=1-e^{-\left(\frac{t}{l}\right)^{m}},
$$

where $m$ and $l$ are the constants to fit using the historical condition records. Additionally, in order to improve the fit, the conditions at the beginning of the asset life $S_{t_{\text {beg }}}=0$ and at the end of life $S_{t_{\text {end }}}=1$ are assumed.

The reliability assessment using Monte Carlo simulations is performed seeking to quantify the impact of an asset failure on the ENS during contingencies. This impact is computed running load flows and considering the load profiles, the expected load growth, and the mean time to repair (MTTR) of each asset. Hence, for every hour of the assumed period of planning, the POF of each asset is evaluated, followed by a load flow running. This calculation is realized in order to assess the security limits during the contingency. The probability of failure is computed using the health index by which the condition assessment is considered. Hence, the criticality associated with the reliability objective is estimated as the cost of the expected ENS during a year due to the failure of an asset. To summarize, trials are performed in order to simulate in a probabilistic way $(\mathrm{N}-\mathrm{POF}(\mathrm{N}))$ the expected ENS for a whole power system during a period of planning. Hence, the probability of failure of each asset is considered. 
Using the results of the Monte Carlo simulation, the density and cumulative functions of the expected energy not supplied are computed to estimate the monetized criticality corresponding to ENS $\left(\mathrm{Cr}_{E N S}\right)$ along the assumed period of planning. In this proposal, the total criticality of the failure is assumed as the monetized impacts:

$$
C r(t)=C r_{E N S}(t)+C r_{F i n}+C r_{E n v}+C r_{\text {Legal }}
$$

where $C r_{F i n}, C r_{E n v}$ and $C r_{\text {Legal }}$ are the financial, environmental, and legal impacts as a consequence of the failure, respectively. These monetized values can be estimated using the regulation and expert knowledge, as suggested by the CIGRE [1]. Finally, the risk matrix is assessed, and subsequently, a priority ranking is performed and presented by a Pareto plot using the risk index.

\subsection{Optimal Decision-Making Assessment}

With the asset fleet ranked by the risk index, and assuming the risk as a financial outcome, the return of investment (ROI) can be stated as follows:

$$
R O I(t)=\frac{\operatorname{Inc}(t)}{R I(t)+O P E X+C A P E X}-1
$$

where $\operatorname{Inc}(t)$ is the estimated revenue for operating the asset at the instant $t$, and OPEX and CAPEX are the assumed constant operating expenses and capital expenses, respectively. In order to assess the optimal decision making, in this paper, we proposed to maximize the ROI by optimizing the maintenance or replacement of a fleet of assets.

\subsubsection{Optimal Replacement Strategy}

In this section, the optimization problem is formulated to estimate the optimal replacement of an asset. Hence, the influence of the replacement on the ROI can be formulated as follows:

$$
R O I(t)=\frac{\operatorname{Inc}(t)}{R I\left(t, t_{\text {rep }}\right)+O P E X+C A P E X}-1
$$

where $t_{r e p}$ is the time when the asset is replaced. To estimate the influence of replacement in the RI with Equation (7), the cumulative failure rate can be expressed as follows:

$$
\int_{t_{\text {beg }}}^{t_{\text {end }}} \lambda(t) d t=\int_{t_{\text {beg }}}^{t_{\text {rep }}}\left(\frac{L}{1+\mathrm{e}^{-k_{1}\left(t-t_{1}+t_{\text {beg }}\right)}}+\lambda_{0}\right) d t+\int_{t_{\text {rep }}}^{t_{\text {end }}}\left(\frac{L}{1+\mathrm{e}^{-k_{2}\left(t-t_{2}+t_{\text {rep }}\right)}}+\lambda_{0}\right) d t
$$

where $t_{1}, t_{2}, k_{1}$, and $k_{2}$ are the cumulative function fit factors for the current and new asset, respectively. Integrating Equation (13), the following expression is obtained:

$$
\begin{aligned}
\int_{t_{\text {beg }}}^{t_{\text {end }}} \lambda(t) d t= & \left(\lambda_{0}+L\right)\left(t_{\text {end }}-t_{\text {beg }}\right)+L\left(\frac{\ln \left(\mathrm{e}^{k_{1}\left(t_{\text {beg }}+t_{1}-t_{\text {rem }}\right)}+1\right)-\ln \left(\mathrm{e}^{k_{1} t_{1}}+1\right)}{k_{1}}+\right. \\
& \left.\frac{\ln \left(\mathrm{e}^{k_{2}\left(t_{\text {rem }}+t_{2}-t_{\text {end }}\right)}+1\right)-\ln \left(\mathrm{e}^{k_{2} t_{2}}+1\right)}{k_{2}}\right)
\end{aligned}
$$

With Equations (6), (7), (11) and (13), the optimization problem is formulated as follows:

$$
\begin{aligned}
\max _{t_{\text {rep }}} & \frac{\operatorname{Inc}(t)}{\left(1-\mathrm{e}^{-\int_{t_{\text {eng }}}^{t_{\text {end }}} \lambda\left(t, t_{\text {rep }}\right) \cdot d t}\right) \cdot C r(t)+\text { OPEX }+C A P E X}-1 \\
\text { s.t. } & t_{\text {rep }}>t_{\text {beg }} \\
\text { s.t. } & t_{\text {rep }}<t_{\text {end }}
\end{aligned}
$$


where the decision variable is the replacement time $\left(t_{r e p}\right)$, and $t_{\text {end }}$ is the assumed life in which the asset generates income.

\subsubsection{Optimal Maintenance Strategy}

In this section, the optimal frequency of maintenance is addressed. The OPEX is taken as the maintenance expenditures given by the maintenance cost times the number of maintenances. As in the previous section, the $\mathrm{ROI}$ is assumed as the objective function as follows:

$$
R O I(t)=\frac{\operatorname{Inc}(t)}{R I(t, T)+\sum_{n=0}^{N-1} M_{c}+C A P E X}-1
$$

where $M_{c}$ is the maintenance cost, $N$ is the amount of maintenance during the asset life, and a constant maintenance period $T$ equivalent to the time between maintenance tasks is assumed. To assume constant $T$, the planning of maintenance in a medium large time is simplified. Hence, the influence of maintenance in the cumulative failure rate is given by

$$
\int_{t_{\text {beg }}}^{t_{\text {end }}} \lambda(t) d t=\sum_{n=0}^{N-1} \int_{0}^{T}\left(\frac{L}{1+\mathrm{e}^{-k\left(t-t_{0}\right)}}+\lambda_{0}\right) d t
$$

where $N=\frac{t_{\text {beg }}-t_{\text {end }}}{T}$. The result of solving the integral of Equation (16), assuming $t_{\text {beg }}=0$, is the following:

$$
\int_{t_{\text {beg }}}^{t_{\text {end }}} \lambda(t) d t=\frac{t_{\text {end }}}{T}\left(\frac{L}{k}\left(\ln \left(\mathrm{e}^{k\left(t_{0}-T\right)}+1\right)-\ln \left(\mathrm{e}^{k t_{0}}+1\right)\right)+T\left(\lambda_{0}+L\right)\right)
$$

Substituting Equation (17) into Equation (15), the optimization problem is given by

$$
\begin{aligned}
\max _{T} & \frac{\operatorname{Inc}(t)}{\left(1-\mathrm{e}^{\int_{0}^{t_{\text {end }}} \lambda(t, T)}\right) \cdot C r(t)+\frac{t_{\text {end }}}{T} \cdot M_{C}+C A P E X}-1 \\
\text { s.t. } & T>0 \\
\text { s.t. } & T<t_{\text {end }}
\end{aligned}
$$

where the decision variable is the maintenance period $(T)$.

\section{Evaluation of the Proposed Procedure}

The proposed procedure is implemented in Python language, in a library called PywerAPM, and evaluated using the IEEE 39 Bus System [21]. Hence, an assessment using the algorithm shown in Figure 2 is performed to model, in a probabilistic way, the impact of a contingency consequence of assets' failures to support the decision making. For this case, in the asset portfolio, only the power transformer fleet was considered. To simplify, the criticality of each transformer is defined as the expected energy not supplied when it fails plus the impact shown in Table 1 . For the simulation, the following conditions were assumed: number of trials $N=750$, starting date 1 January 2020, planning period of 10 years equivalent to $87,600 \mathrm{~h}$, and load growth rate of $2 \% /$ year. The load patterns and the records of transformer diagnostic tests were provided by a local utility. 
Table 1. Assumed criticality for the asset fleet.

\begin{tabular}{cccc}
\hline Asset & $C \boldsymbol{r}_{\text {Fin }}$ & $\mathrm{Cr}_{\text {Env }}$ & $\mathrm{Cr}_{\text {Legal }}$ \\
\hline TR_1 & $8.40 \times 10^{4}$ & & $1.00 \times 10^{5}$ \\
TR_2 & $1.20 \times 10^{5}$ & & \\
TR_3 & $1.20 \times 10^{5}$ & $1.00 \times 10^{3}$ & \\
TR_4 & $9.60 \times 10^{4}$ & $1.00 \times 10^{3}$ & \\
TR_5 & $8.40 \times 10^{4}$ & & \\
TR_6 & $9.60 \times 10^{4}$ & & \\
TR_7 & $1.20 \times 10^{5}$ & & \\
TR_8 & $7.20 \times 10^{4}$ & & \\
TR_9 & $3.60 \times 10^{4}$ & & \\
TR_10 & $9.60 \times 10^{4}$ & & \\
TR_11 & $3.60 \times 10^{4}$ & & \\
TR_12 & $8.40 \times 10^{4}$ & $2.00 \times 10^{3}$ & \\
\hline
\end{tabular}

\subsection{System Description}

The IEEE 39 Bus System is composed of 19 loads, 10 generators, 34 lines, and 12 power transformers. The system topology is shown in Figure 3. The rating of power transformers and lines was assumed constant, making a conservative assumption. In other words, dynamic rating was not considered.

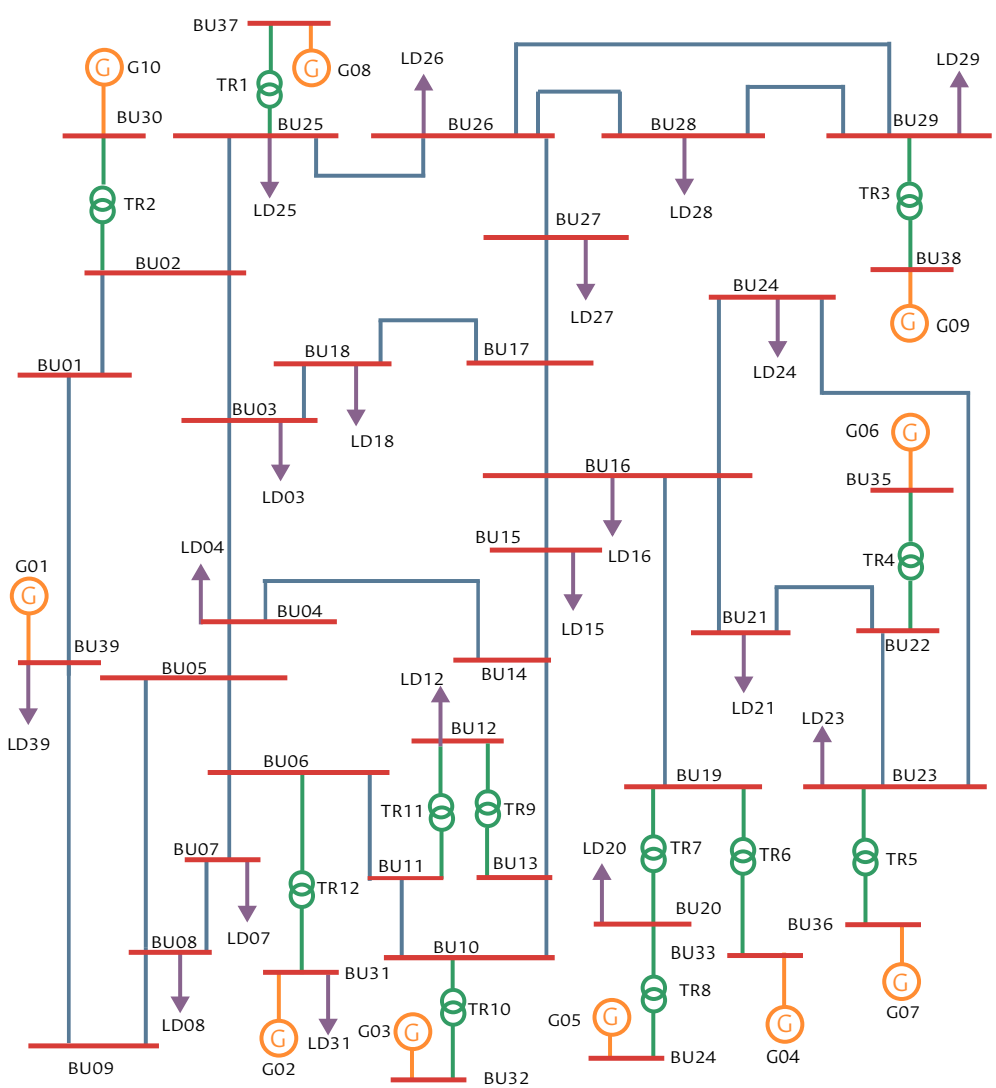

Figure 3. Transmission System of IEEE 39 New England Bus System [21].

The operating conditions of the assumed power system during the first week of the period of planning are shown in Figure 4. These conditions were computed following the procedure proposed in [22]. Figure 4a,b shows the assumed load profiles for each of the 19 loads on Wednesday and Sunday. These are considered as the days with a higher difference in the load patterns. The load profiles were approximated using Fourier series, such as 
addressed in [23]. The loading of the transformers and lines as well as the voltages of the buses were computed using the pandapower tool [24] by running load flows at each hour.

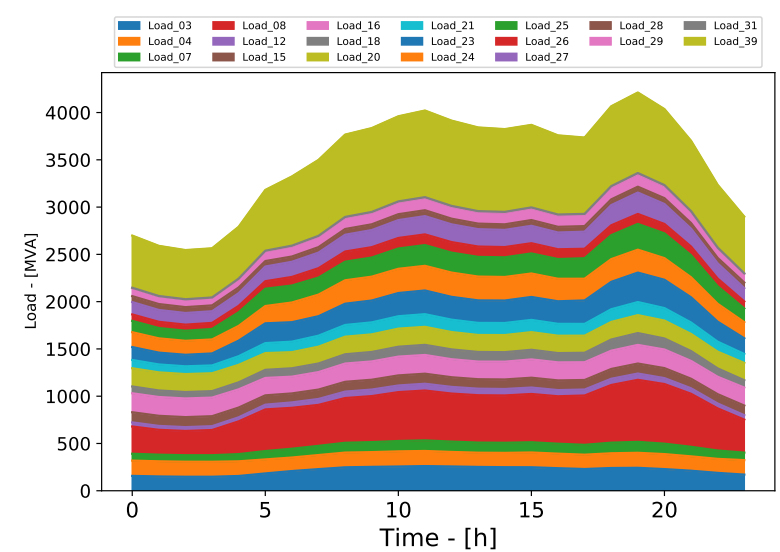

(a) Power forecasting on Wednesday

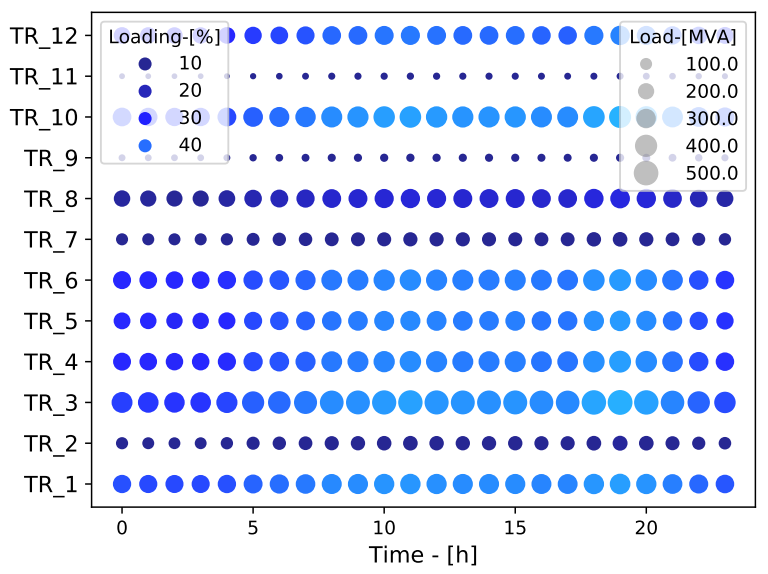

(c) Loading of TR on Wednesday

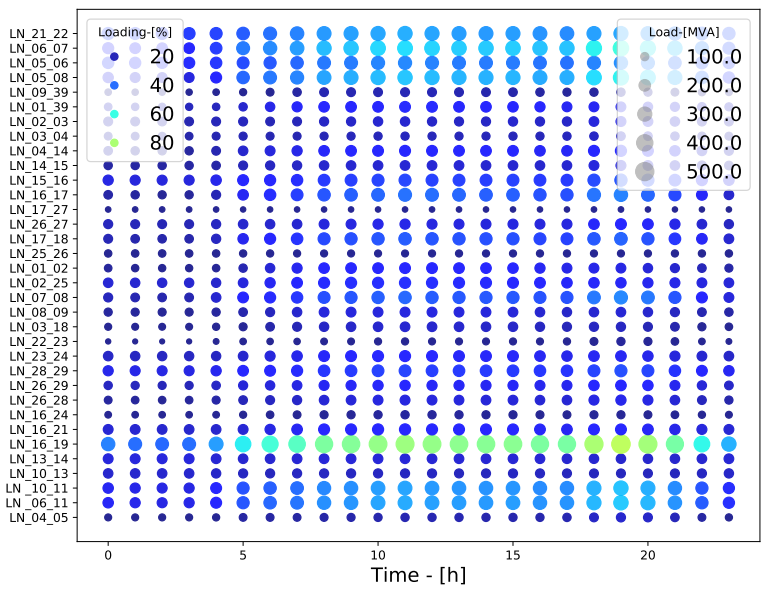

(e) Loading of OHL on Wednesday

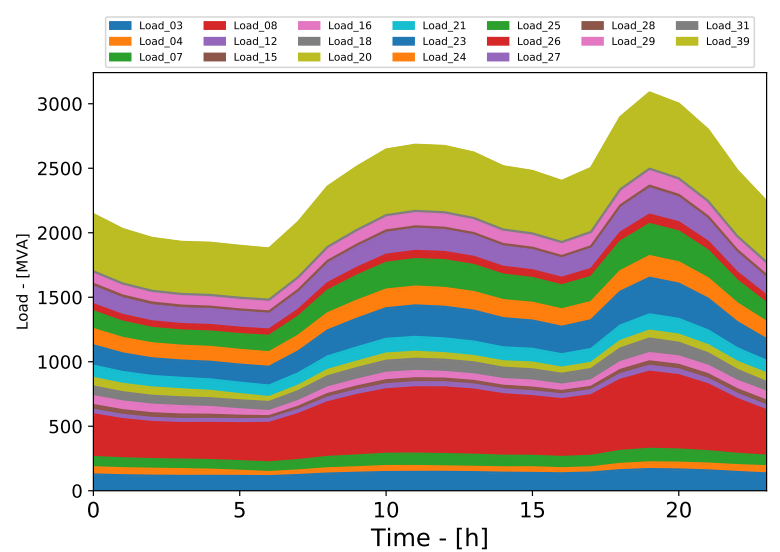

(b) Power forecasting on Sunday

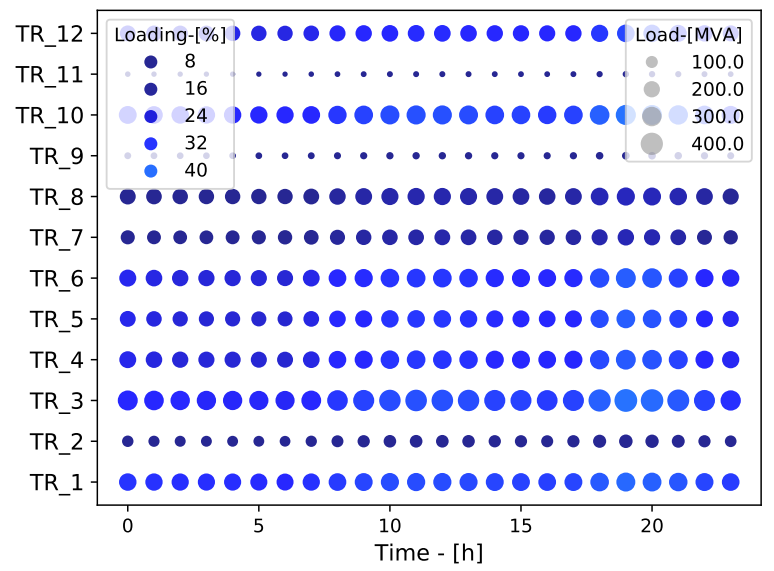

(d) Loading of TR on Sunday

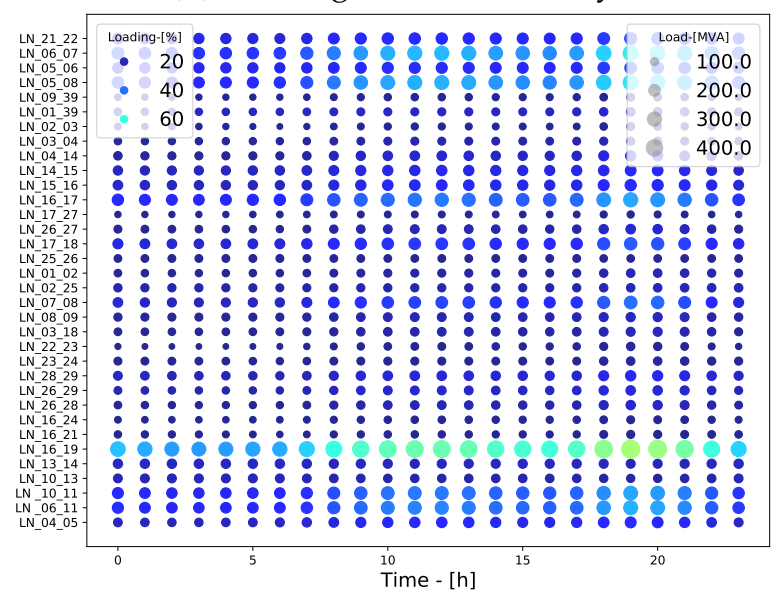

(f) Loading of OHL on Sunday

Figure 4. Cont. 


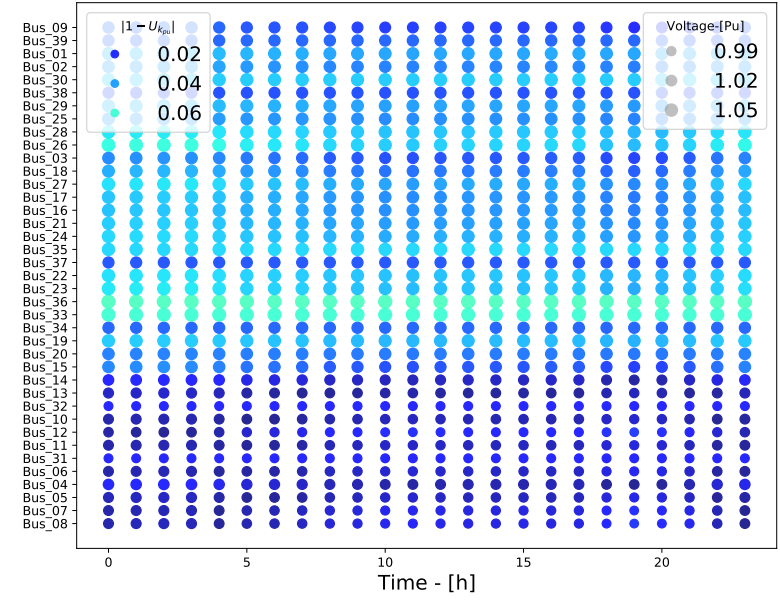

(g) Vol. of buses on Wednesday

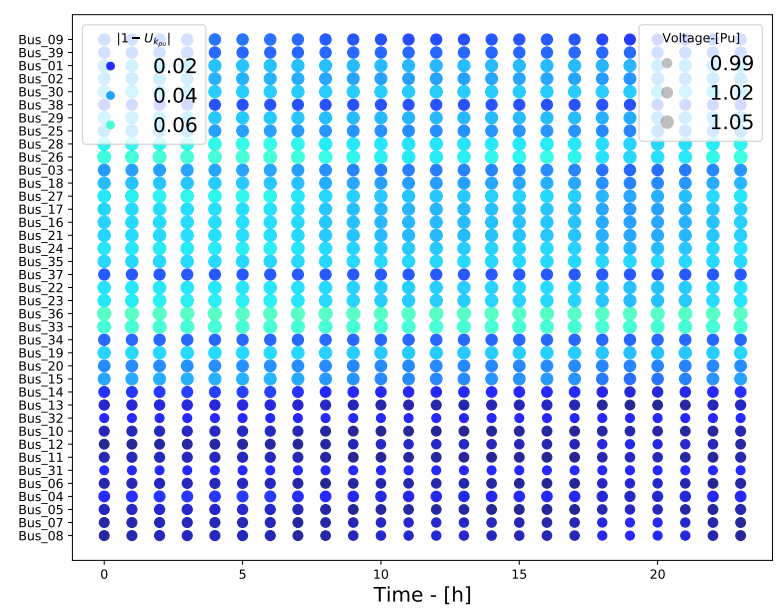

(h) Vol. of buses on Sunday

Figure 4. Operating conditions assuming a normal operation of the IEEEE 39 Bus System and considering load forecasting for the first assessed week.

As security margins, a conservative loading less than $100 \%$ for lines and transformers was assumed, and to simplify, dynamic ratings were not considered. For buses, the voltage limits are from $0.9 \mathrm{pu}$ to $1.1 \mathrm{pu}$. In Figure $4 \mathrm{c}, \mathrm{d}$, it can be appreciated that the transformers TR_1, TR_3, TR_4, TR_5, TR_6, and TR_10 are close to $50 \%$ of their loading during load peak operation. Additionally, by these transformer flows, the maximum peak power is close to 500 MVA. Figure 4e,f shows the loading of lines. Here, it can be appreciated that the LN_16_19 is operating close to its security margin with a power flow near 500 MVA. Finally, Figure 4g,h shows the voltage assessment where Bus_36 and Bus_33 are close to their upper limit.

\subsection{Power Transformer Conditions}

To assess the condition of the transformer fleet, historical diagnostic records of a local utility were used. Figure 5 shows the records of total dissolved combustible gas (TDCG), the furan $2 \mathrm{FAL}$, and the dielectric breakdown voltage (DS). In particular, Figure 5 a presents the assessment of TDGC using the IEEE Std C57.104 ${ }^{\mathrm{TM}}-2008$ [25], and it can be noted that the condition of TR_5 indicates that the transformer has been heavily overloaded, and/or an arc has occurred inside. A similar behavior of this transformer is shown in the records of the furan 2FAL. According to Figure 5b, the transformers TR_3, TR_10, and TR_12 present a historical increasing rate of the furan 2FAL. Finally, the records of dielectric breakdown voltage are shown in Figure 5c. These records were assessed according to IEEE Std C57.152 ${ }^{\mathrm{TM}}-2013$ [26] and demonstrate that almost all of the transformer fleet is outside of the acceptable margin, and an accelerated degradation of the assets can occur in the lifetime. 

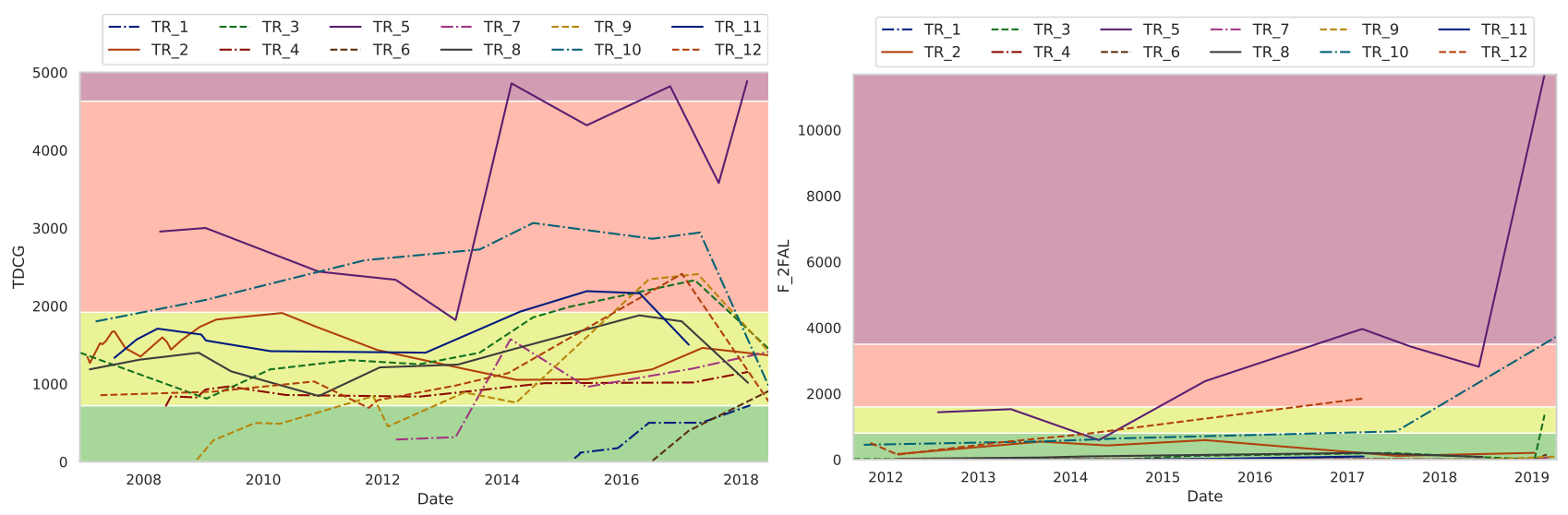

(a) Records of total dissolved combustible gas TDCG in ppm for the 12 power transformers

(b) Records of furan 2FAL in ppm for the 12 power transformers

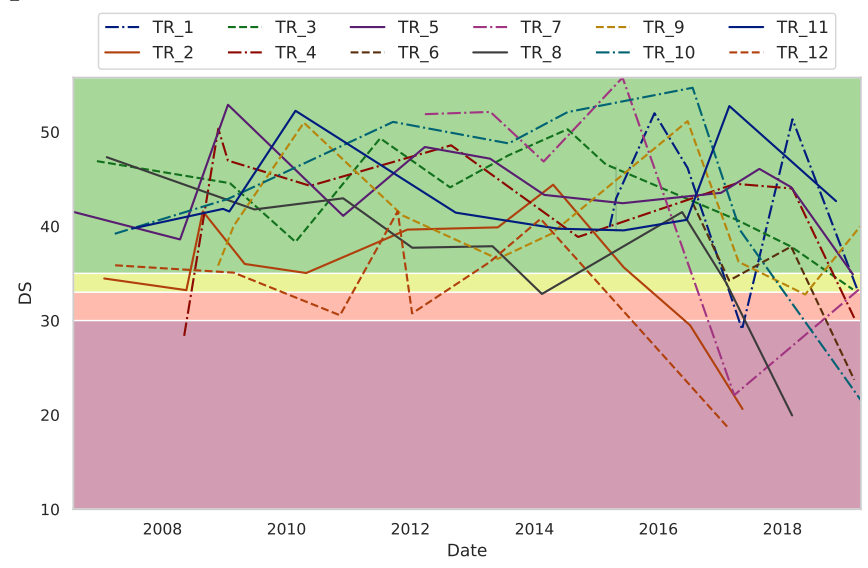

(c) Records of dielectric breakdown voltage in $\mathrm{kV} \mathrm{mm}^{-1}$ for the 12 power transformers

Figure 5. Historical diagnostic test of the power transformers.

\subsection{Condition Assessment}

In order to estimate the transformer health index, each condition assessment is normalized from 0 to 1 , where 0 is the score with the best condition, or as new, and 1 is the worst condition score. To illustrate, a value of dielectric breakdown voltage greater than $55 \mathrm{kV} \mathrm{mm}^{-1}$ will be scored with 0 and a value close to 0 will be scored with 1 , using the IEEE Std C57.152 ${ }^{\mathrm{TM}}-2013$. Additionally, considering that the condition records are reported on different dates, a curve fit using (8) is performed in order to predict the asset condition. Hence, the normalized condition of power transformers is assessed using the tables reported in [27], and the curve fit is performed using the condition records and the Python library SciPy [28]. With these normalized conditions, the health index is computed using Equation (1). To illustrate this procedure, the normalized conditions of transformers TR_2, TR_3, and TR_12 are predicted for the years 2020, 2021, 2025, and 2030 and exposed in Figure 6. These dates correspond to the assumed periods for planning maintenance (2020), refurbishment (2025), and replacement (2030) of a power transformer fleet. Here, it can be appreciated that the transformers present differences in the number of diagnostics tests, i.e., by the current policies of maintenance of the asset owner by which the kind of diagnostic for each transformer is defined. 


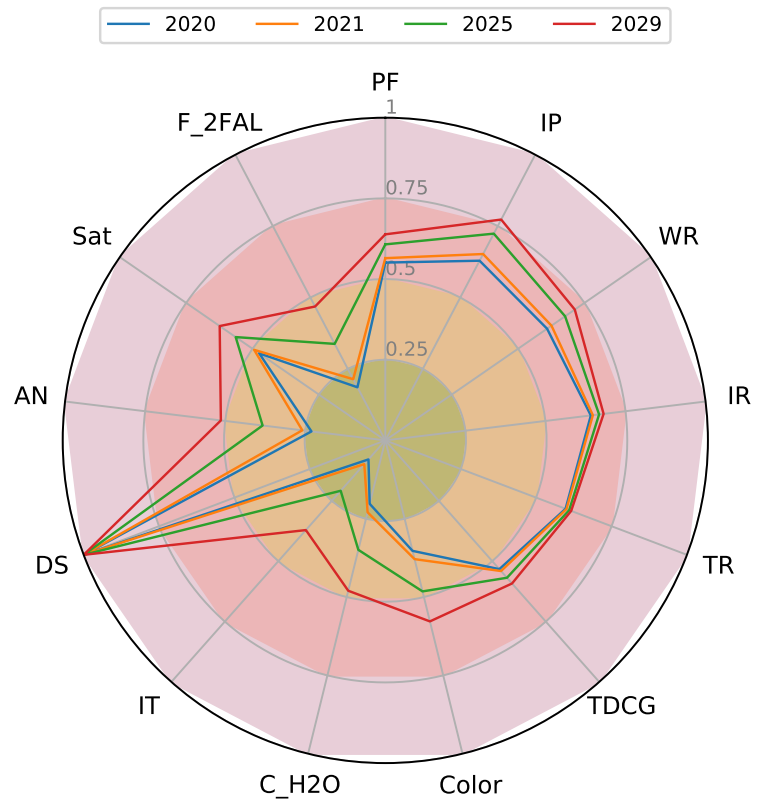

(a) Condition forecasting for the transformer TR_2

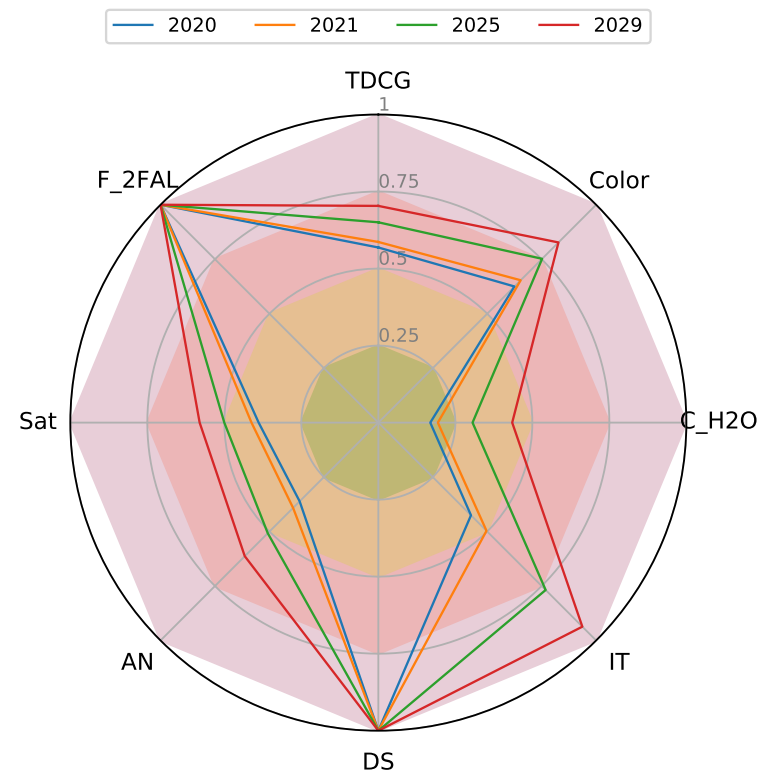

(b) Condition forecasting for the transformer TR_3

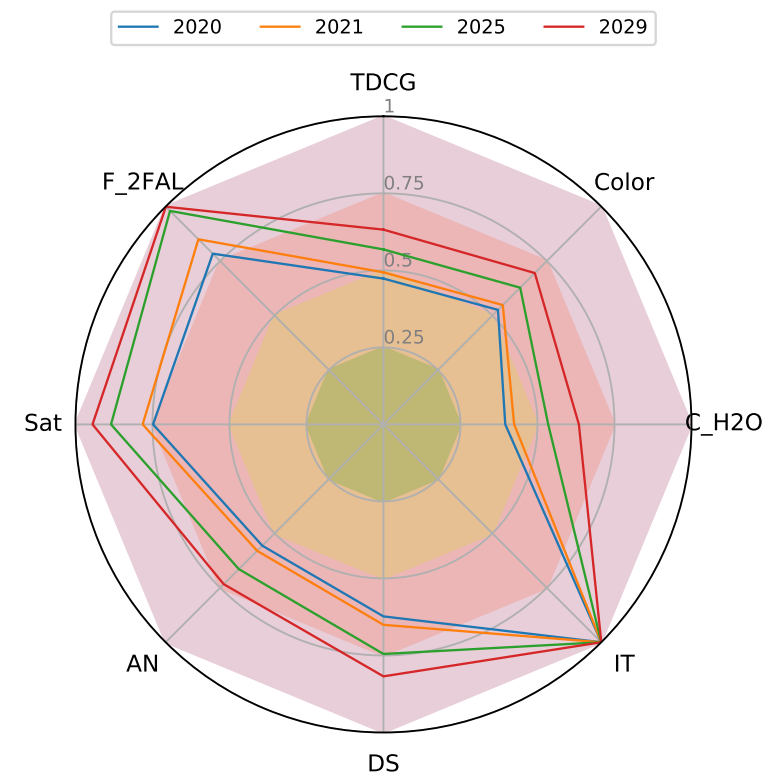

(c) Condition forecasting for the transformer TR_12

Figure 6. Normalized diagnostic condition assessment of the power transformer fleet of IEEE 36 Bus System transmission, where C_H20, PF, IP, WR, IR, TR, IT, AN, and SAT are water content, power factor, polarization index, winding resistance, insulation resistance, winding ratio, interfacial tension, acidity, and relative saturation, respectively.

To assess the transformer condition using the health index Equation (1), the normalized historical diagnostic records are employed. The weights $(\omega)$ used for each condition are presented in [27]. Table 2 shows the estimated HI for the power transformer fleet during the assuming periods of planning. Here, it can be appreciated that the transformers TR_1 and TR_11 present the highest rise of degradation, increasing from 0.24 to 0.53 and from 0.4 to 0.72 , respectively. 
Table 2. Condition assessment forecast using health index.

\begin{tabular}{lcccc}
\hline TR Rating-[S] & $\mathbf{2 0 2 0}$ & $\mathbf{2 0 2 1}$ & $\mathbf{2 0 2 5}$ & $\mathbf{2 0 2 9}$ \\
\hline TR_1 700 MVA & 0.24 & 0.31 & 0.48 & 0.53 \\
TR_2 1000 MVA & 0.50 & 0.52 & 0.58 & 0.63 \\
TR_3 1000 MVA & 0.69 & 0.70 & 0.77 & 0.82 \\
TR_4 800 MVA & 0.47 & 0.48 & 0.53 & 0.57 \\
TR_5 700 MVA & 0.81 & 0.82 & 0.87 & 0.89 \\
TR_6 800 MVA & 0.33 & 0.40 & 0.50 & 0.54 \\
TR_7 1000 MVA & 0.56 & 0.57 & 0.62 & 0.66 \\
TR_8 600 MVA & 0.41 & 0.43 & 0.52 & 0.61 \\
TR_9300MVA & 0.55 & 0.57 & 0.65 & 0.73 \\
TR_10 800 MVA & 0.75 & 0.76 & 0.79 & 0.82 \\
TR_11 300 MVA & 0.40 & 0.48 & 0.68 & 0.72 \\
TR_12 700 MVA & 0.61 & 0.65 & 0.74 & 0.79 \\
\hline
\end{tabular}

Subsequently, the rate of failure $(\lambda(t))$ is estimated with (2) using the health index. The constants assumed to estimate $\lambda$ are shown in Table 3 . However, these constants should be estimated with both condition and failure records of the utility when the data are available. Finally, once the failure rate is calculated, the reliability and therefore the probability of failure are computed. In Figure $7 \mathrm{a}, \mathrm{HI}$ predictions are shown, whereas Figure $7 \mathrm{~b}$ pictures the cumulative probability forecast of failure for each asset.

Table 3. Constants to estimate transformer failure rate [20].

\begin{tabular}{cccc}
\hline TR Rating-[S] & a & $\begin{array}{c}\text { Constant } \\
\mathbf{b}\end{array}$ & $\mathbf{c}$ \\
\hline $\mathrm{S} \leq 25 \mathrm{MVA}$ & 0.01565 & 2.2478602 & -0.008148 \\
$\mathrm{~S}>25 \mathrm{MVA}$ & 0.00962 & 2.5618677 & -0.004615 \\
\hline
\end{tabular}

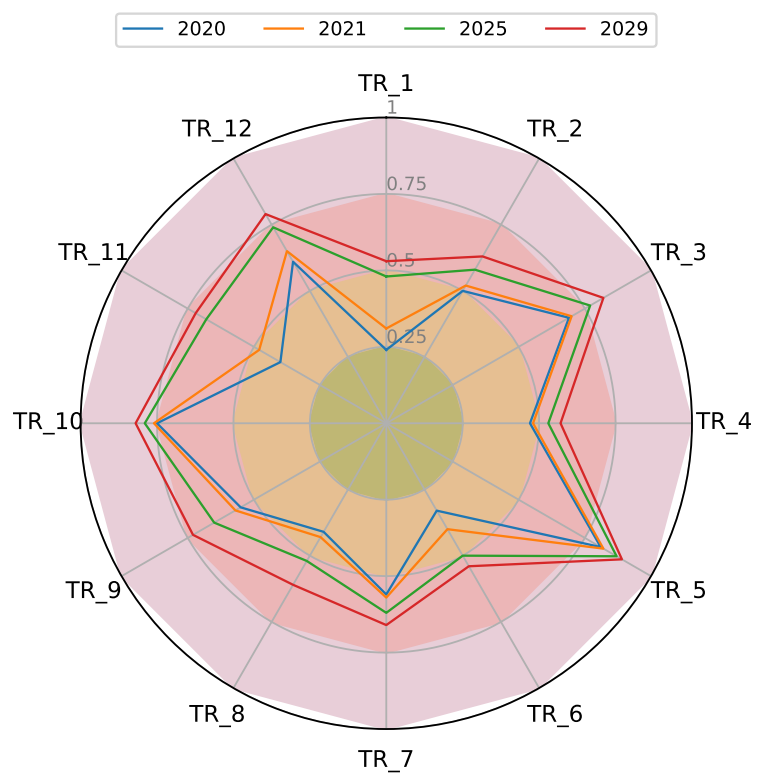

(a) HI-Health Index

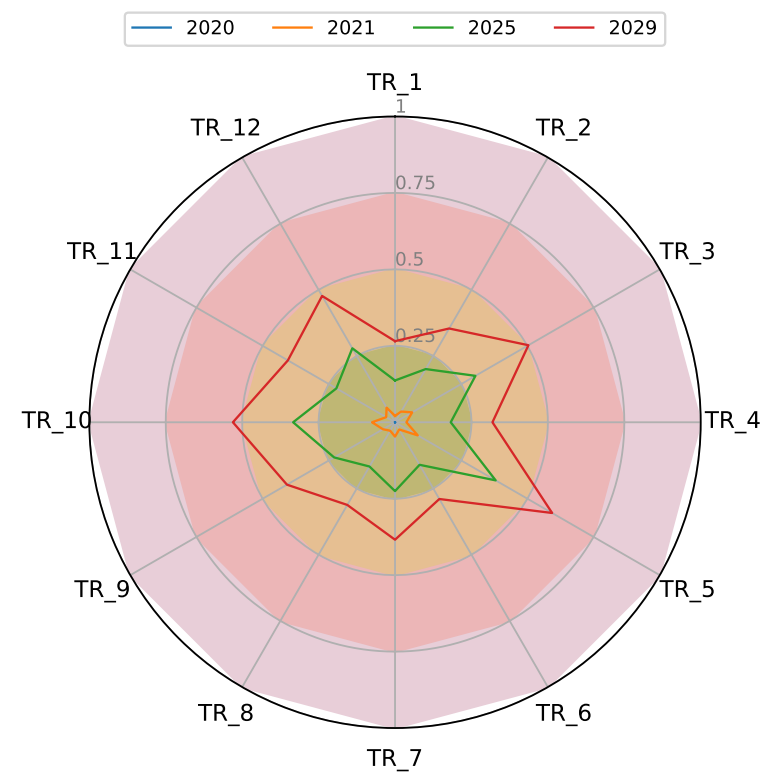

(b) Cumulative Probability of Failure

Figure 7. Health index prediction and cumulative probability forecast of failure for the transformer fleet. 


\subsection{Reliability Assessment}

The risk assessment can be addressed as the criticality times the POF, according to (7). An objective of the criticality assessment in electric systems is the quantification of the expected cost by energy not supplied (ENS) as a result of an asset failure. Nevertheless, as a consequence of power demand variation depending on the hour, day, week, and year, the ENS when an asset fails depends on the operating conditions during the failure as well as the time to repair. In this case, on the one hand, a mean time for repair (MTTR) of $8 \mathrm{~h}$ and of $16 \mathrm{~h}$ for transformers located close to generators (step up) and for transmission transformers (step down) was assumed, respectively. These times consider the use of mobile substations or substitute transformers, commonly employed at the transmission level. On the other hand, the expected ENS was estimated performing the Monte Carlo simulation shown in the algorithm of Figure 2. This reliability assessment can be called $N-\operatorname{POF}(N)$. The simulation results are shown in Figures 8 and 9, where both histograms of the cumulative density of expected ENS and the ENS cumulative probability can be appreciated for the entire power system. Figure 9 shows with vertical lines the cumulative probability of 85,95 , and $99 \%$ for each period of planning. The cumulative expected energy not supplied is shown in Table 4.

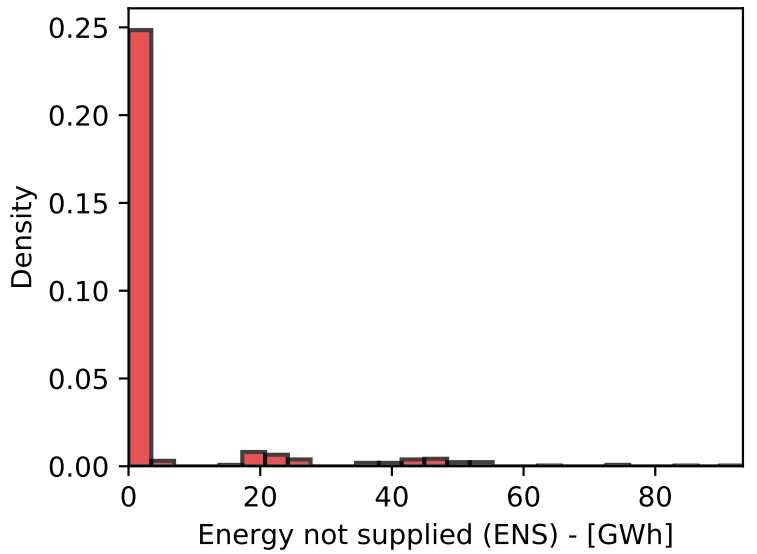

(a) 2020

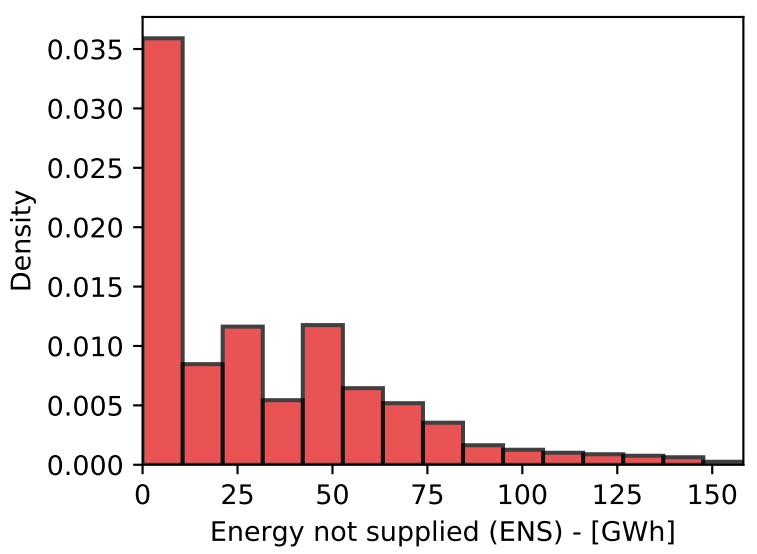

(c) 2025

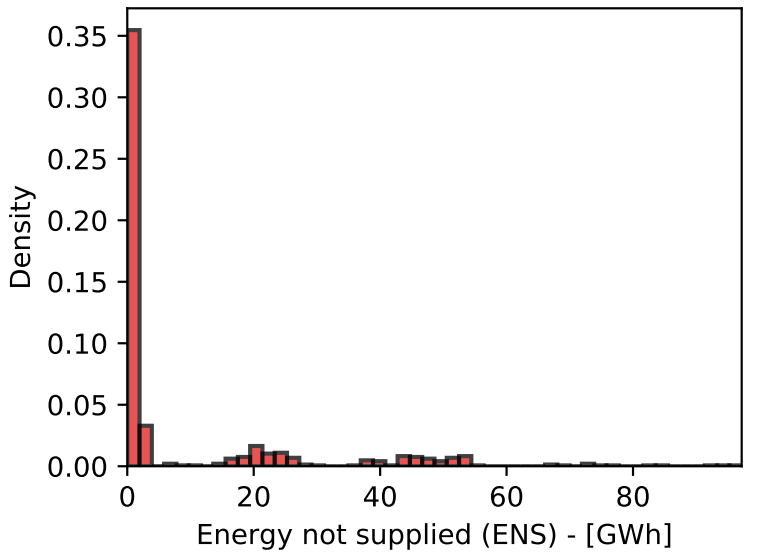

(b) 2021

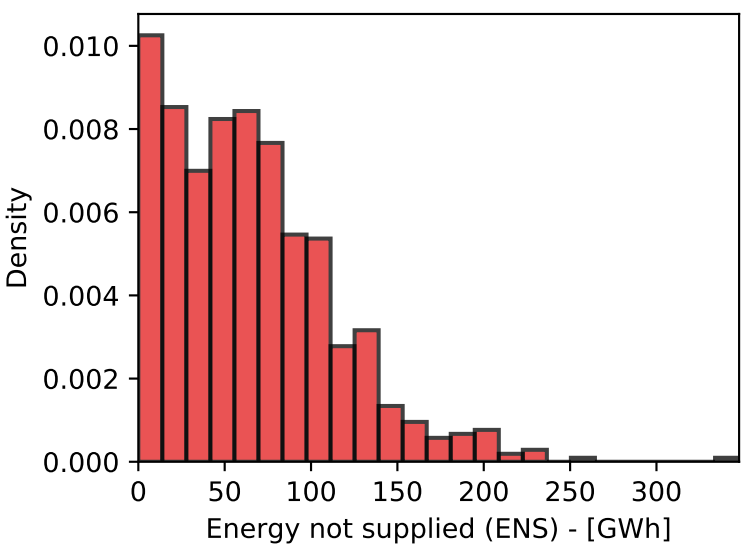

(d) 2029

Figure 8. Histogram of the expected accumulated energy not supplied for each period of planning. 


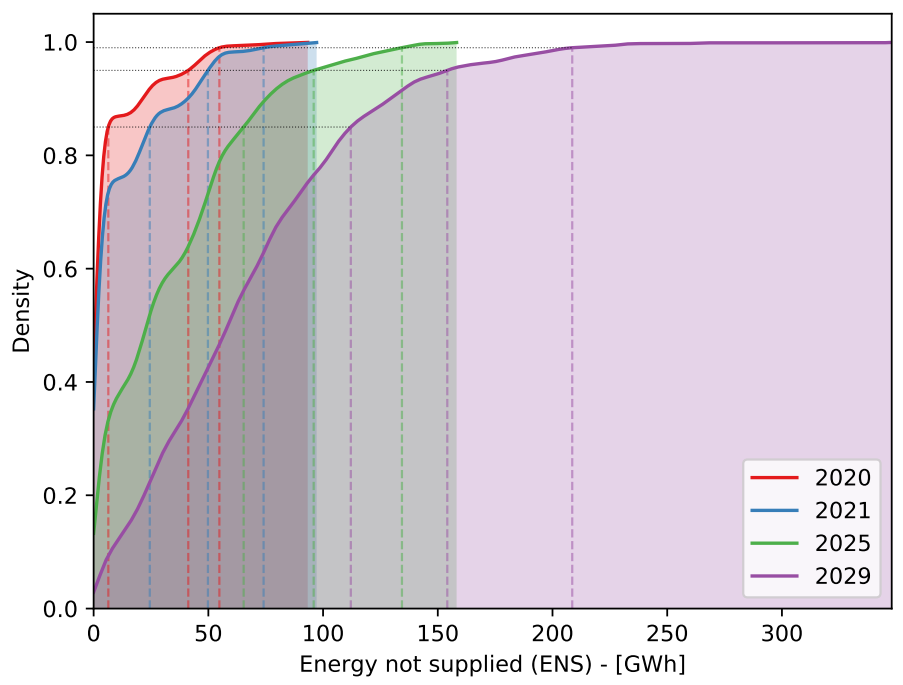

Figure 9. Cumulative probability of the expected energy not supplied by year.

Table 4. Cumulative probability of the expected energy not supplied.

\begin{tabular}{cccc}
\hline \multirow{2}{*}{ Year } & \multicolumn{3}{c}{ Cumulative ENS-GW h } \\
& $\mathbf{8 5 \%}$ & $\mathbf{9 5 \%}$ & $\mathbf{9 9 \%}$ \\
\hline 2020 & 6.4 & 41.2 & 54.8 \\
2021 & 24.5 & 49.8 & 74.1 \\
2025 & 65.4 & 95.9 & 134.4 \\
2029 & 112.1 & 154.1 & 208.6 \\
\hline
\end{tabular}

\subsection{Risk Assessment}

In order to assess the contribution of an asset failure in the entire risk of the whole power system, violin plots are performed as shown in Figure 10. In these plots, the cumulative expected ENS associated with each transformer failure is compared with the cumulative ENS of the fleet during the assumed periods of planning.

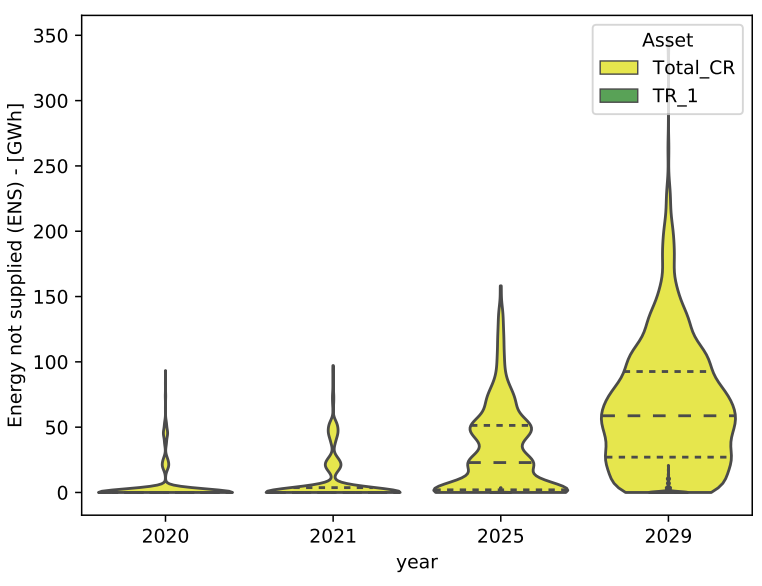

(a) Impact of TR_1 on the ENS

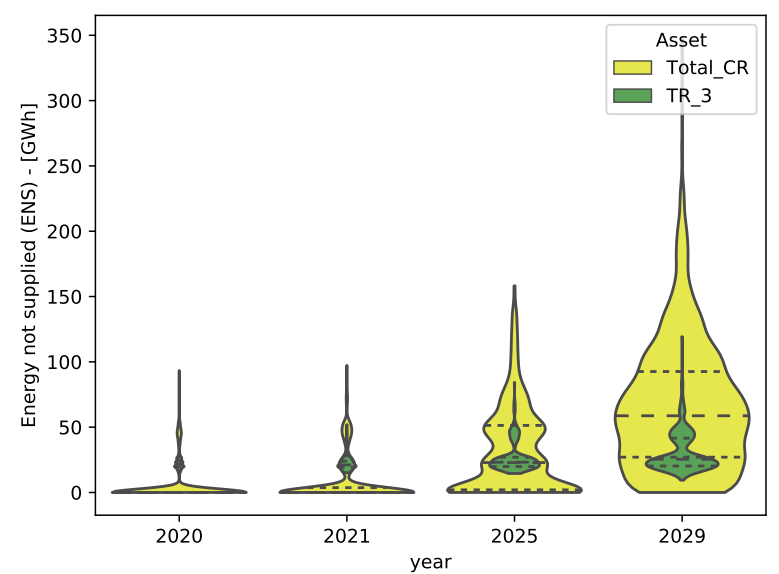

(b) Impact of TR_3 on the ENS

Figure 10. Cont. 


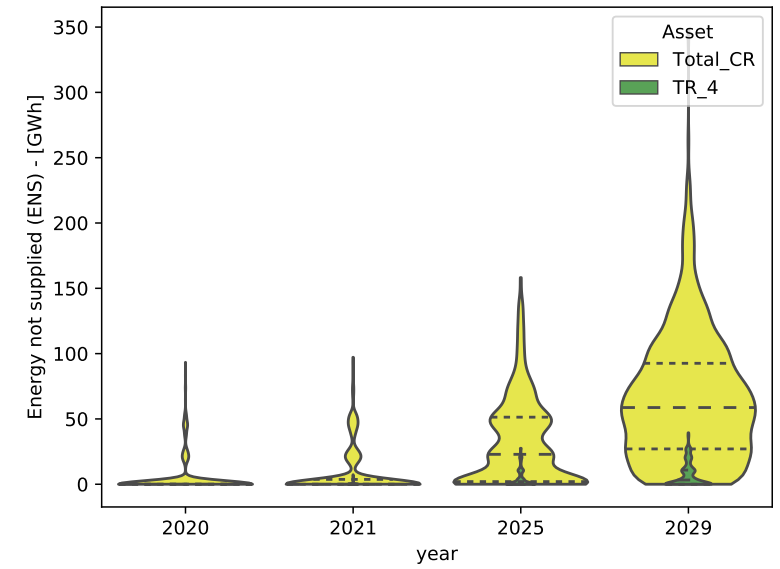

(c) Impact of TR_4 on the ENS

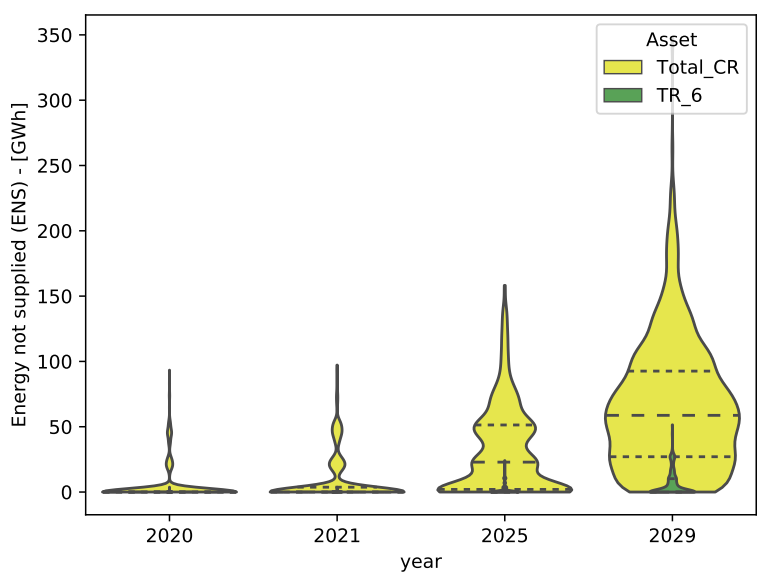

(e) Impact of TR_6 on the ENS

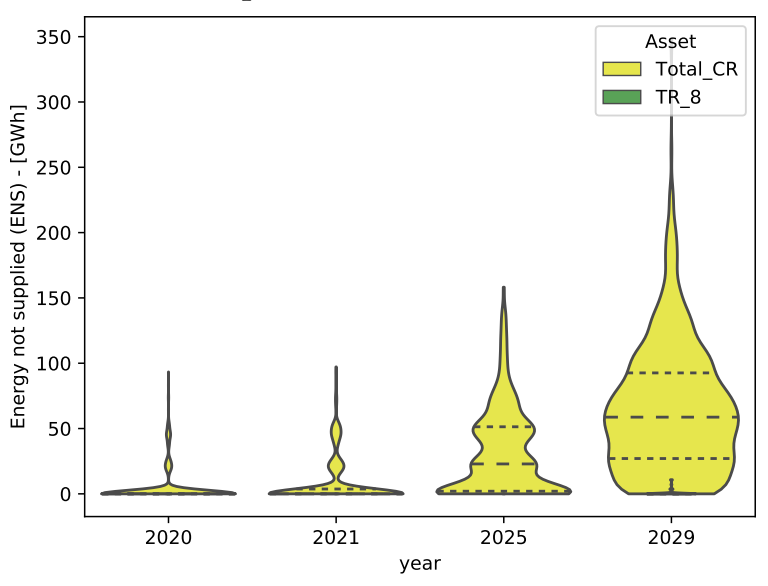

(g) Impact of TR_8 on the ENS

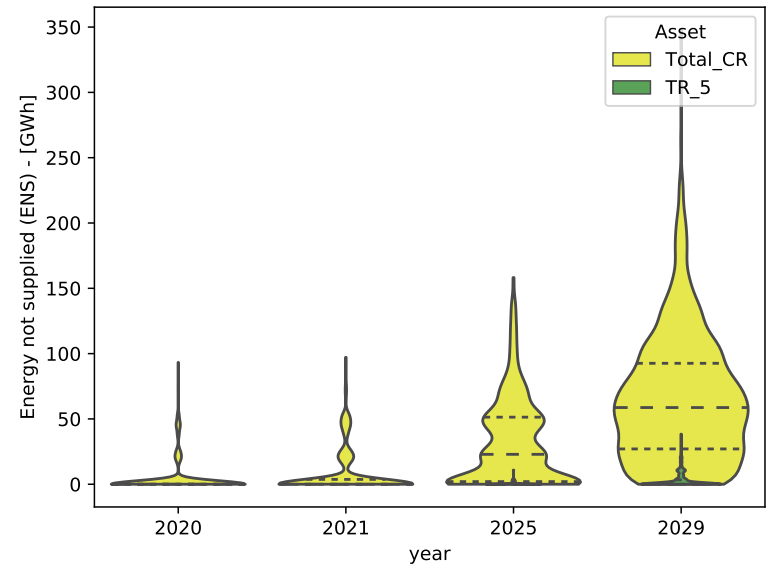

(d) Impact of TR_5 on the ENS

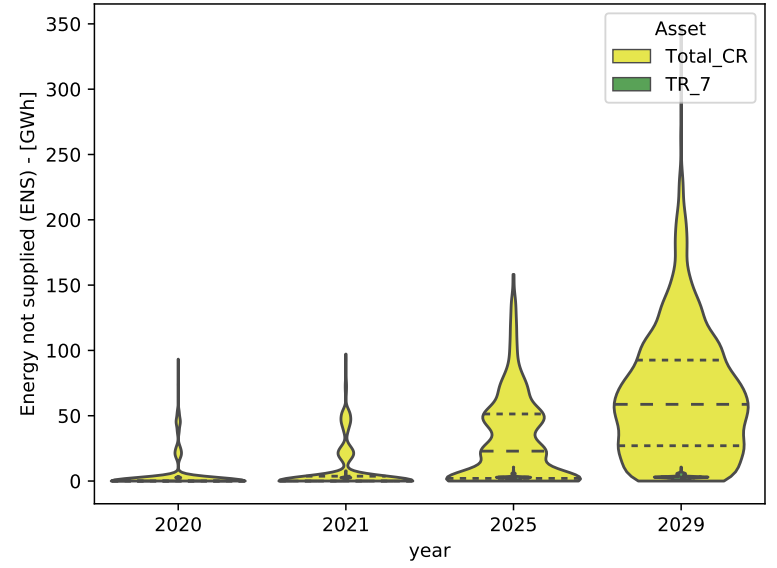

(f) Impact of TR_7 on the ENS

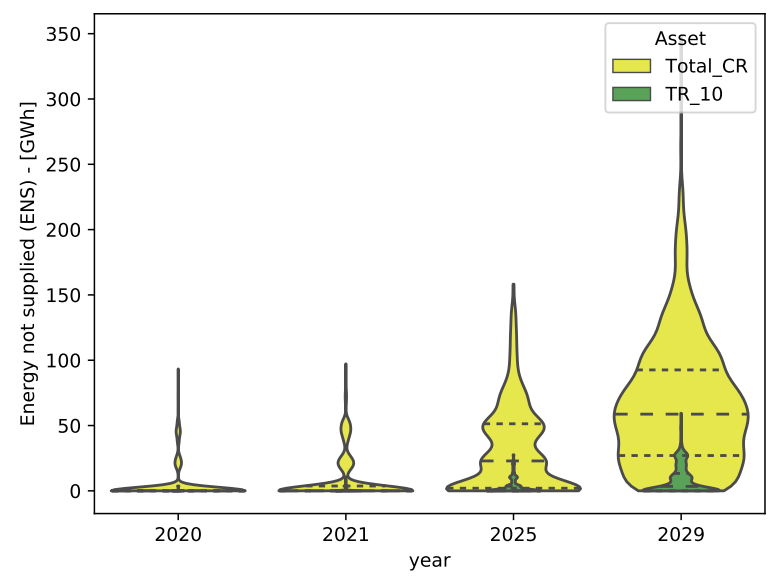

(h) Impact of TR_10 on the ENS

Figure 10. Cont. 


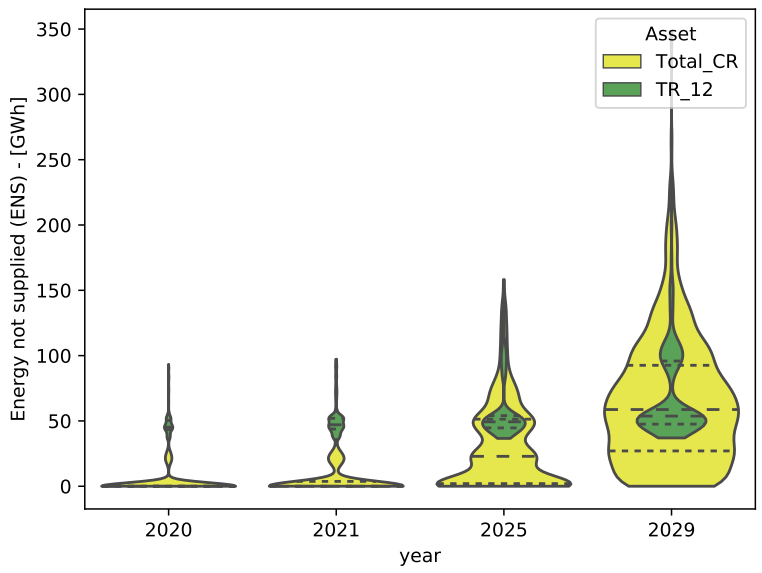

(i) Impact of TR_12 on the ENS

Figure 10. Impact of asset fleet failures on the cumulative expected ENS.

In Figure 10i, it can be appreciated that the transformer TR_12 has the highest impact on the total ENS of the system. Additionally, this asset presents the highest contingency impact as a result of its failure, with a cumulative expected ENS close to $350 \mathrm{GW}$ h. However, this result is a consequence of the transformer function, since TR_12 is the link between the transmission system and the generator $\mathrm{G} 02$, which was assumed as the slack for running load flows.As future work, a power rescheduling strategy must be included for the assessment. The second transformer with the highest expected impact on the risk of the system is the TR_3. In Figure 10b, it can be observed that all failures of this transformer produced contingencies, and therefore the energy not supplied is expected for all studied cases (inner violin plot always has values greater than 0 ). On the contrary, transformers TR_5 and TR_6 (Figure 10d,e) present a high failure rate, but their impact on the risk assessment of the whole system is lower for almost all failures. Finally, the expected failures of transformers TR_2, TR_9, and TR_11 do not impact the risk and therefore do not cause ENS. For this reason, their violin plots are not shown.

Figure 11 shows the predicted risk matrix of the transformer fleet during each year of the periods of planning assumed. The criticality for each transformer was assumed as the root mean square of the ENS associated with its failure. The size of the circles represent the MTTR assumed for each asset, and the color represents the risk index.

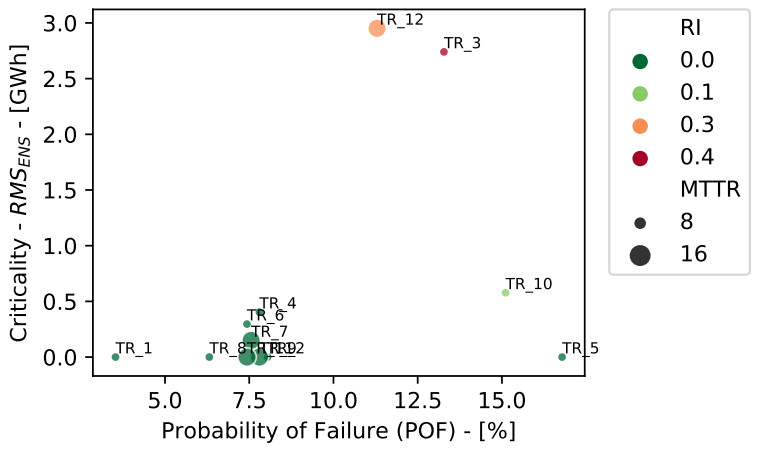

(a) 2021

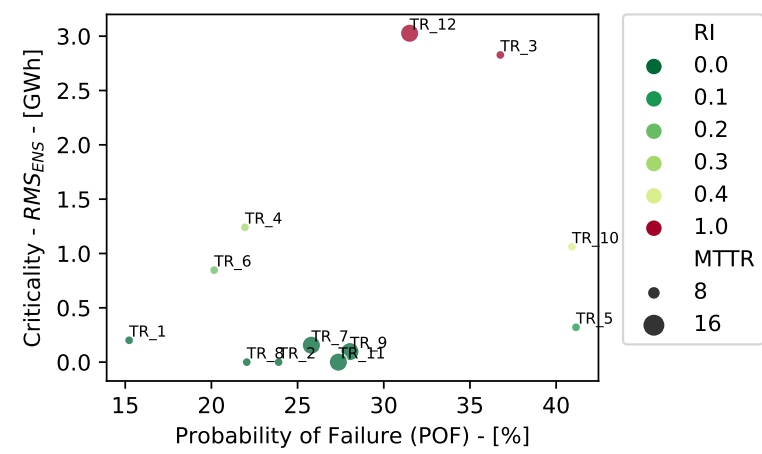

(b) 2025

Figure 11. Cont. 


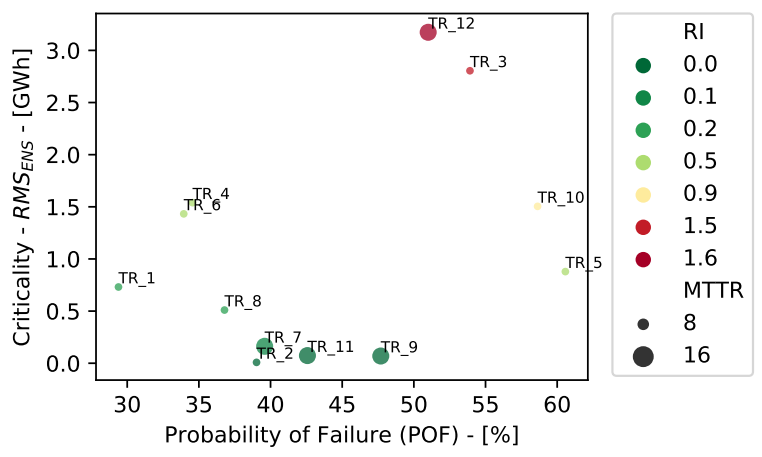

(c) 2029

Figure 11. Transformer fleet risk matrix for the assumed periods of planning.

Finally, Figure 12 shows the risk index using a Pareto ranking during the assumed periods of planning. Only the assets with $R I>0$ by ENS are shown. Here, it can be appreciated that the transformers TR_3 and TR_12 present the highest risk. On the one hand, it is estimated that the TR_5 shows the highest risk increase by ENS, and on the other hand, the TR_7 presents the lowest increase. These types of analyses can be used to support decision making. For instance, in the year 2021, the prioritized decision over the fleet should be related to TR_3 and TR_12. Subsequently, in the year 2025, the prioritized transformers should be TR_10, TR_4, and TR_6. This decision making must consider budgetary constraints as well as a positive opportunity. The opportunity is measured as the risk reduction monetized to carried out the decision minus the cost of it.

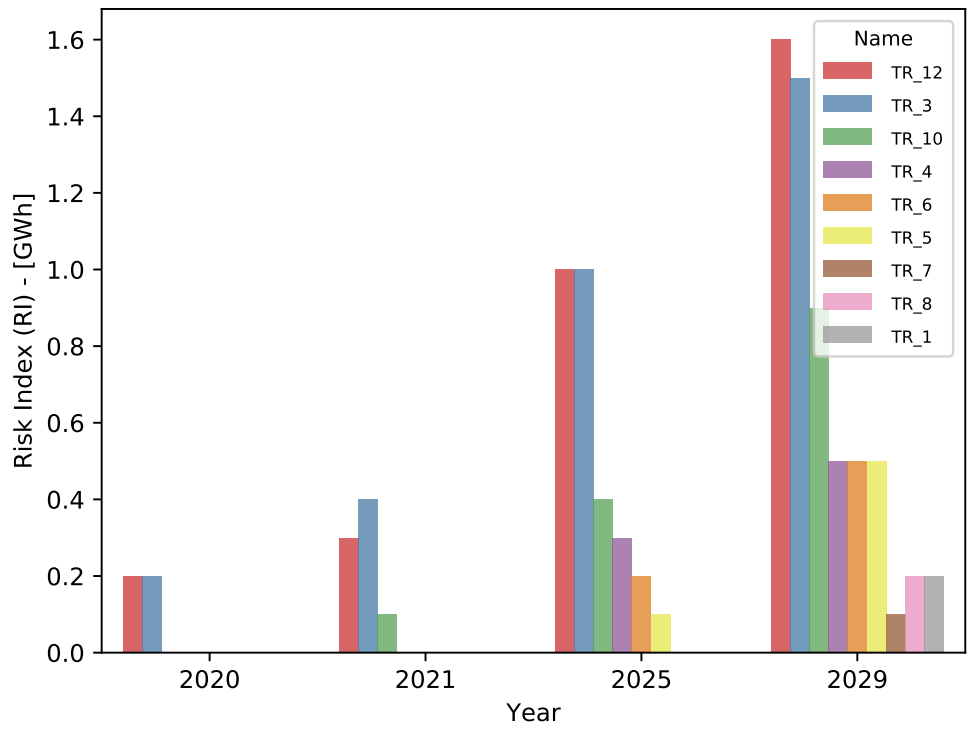

Figure 12. Asset fleet risk index ranking for the assumed periods of planning.

\subsection{Optimal Decision Making}

With the model for forecasting the risk index, the optimal asset replacement and maintenance frequency are estimated assuming a regulatory life of 35 years. The financial variables are shown in Table 5. 
Table 5. Assumed financial parameters for the asset fleet.

\begin{tabular}{ccrr}
\hline Asset & CAPEX [\$] & OPEX- $\boldsymbol{M}_{\boldsymbol{C}}$ [\$] & Income Per Year [\$] \\
\hline TR_1 & $63 \times 10^{3}$ & $1.4 \times 10^{3}$ & $7 \times 10^{3}$ \\
TR_2 & $90 \times 10^{3}$ & $2 \times 10^{3}$ & $10 \times 10^{3}$ \\
TR_3 & $90 \times 10^{3}$ & $2 \times 10^{3}$ & $10 \times 10^{3}$ \\
TR_4 & $72 \times 10^{3}$ & $1.6 \times 10^{3}$ & $8 \times 10^{3}$ \\
TR_5 & $63 \times 10^{3}$ & $1.4 \times 10^{3}$ & $7 \times 10^{3}$ \\
TR_6 & $72 \times 10^{3}$ & $1.6 \times 10^{3}$ & $8 \times 10^{3}$ \\
TR_7 & $90 \times 10^{3}$ & $2 \times 10^{3}$ & $10 \times 10^{3}$ \\
TR_8 & $54 \times 10^{3}$ & $1.2 \times 10^{3}$ & $6 \times 10^{3}$ \\
TR_9 & $27 \times 10^{3}$ & $0.6 \times 10^{3}$ & $3 \times 10^{3}$ \\
TR_10 & $72 \times 10^{3}$ & $1.6 \times 10^{3}$ & $8 \times 10^{3}$ \\
TR_11 & $27 \times 10^{3}$ & $0.6 \times 10^{3}$ & $3 \times 10^{3}$ \\
TR_12 & $63 \times 10^{3}$ & $1.4 \times 10^{3}$ & $7 \times 10^{3}$ \\
\hline
\end{tabular}

To estimate both optimal replacement and maintenance frequency, the formulations given by Equations (14) and (18) were implemented in the SciPy optimization package [28].

\subsubsection{Optimal Replacement}

The optimal replacement time for the entire fleet compared with not replacing the asset is shown in Figure 13. According to the results, here, it can be appreciated that the highest benefit is replacing the TR_1 in the year 7.7. This decision is a result of the associated legal impact shown in Table 1, which is the highest of the fleet. A similar assessment is done for the transformer TR_10. The second decision with the best benefit is related to transformer TR_12, because this asset has both a high criticality by ENS and a poor condition. In other words, it presents a high risk index as can be appreciated in Figure 12. For TR_12, the result of not replacing it (do nothing) is a negative ROI. The next decisions with a positive benefit are changing the assets TR_9, TR_11, and TR_6 at years 5.9, 6, and 7.3, respectively. For the rest of the assets, the optimal decision is to do nothing and therefore assume taking the risk. The benefit is assumed as the difference between ROI of the optimal replacement time and the ROI of the do nothing decision.

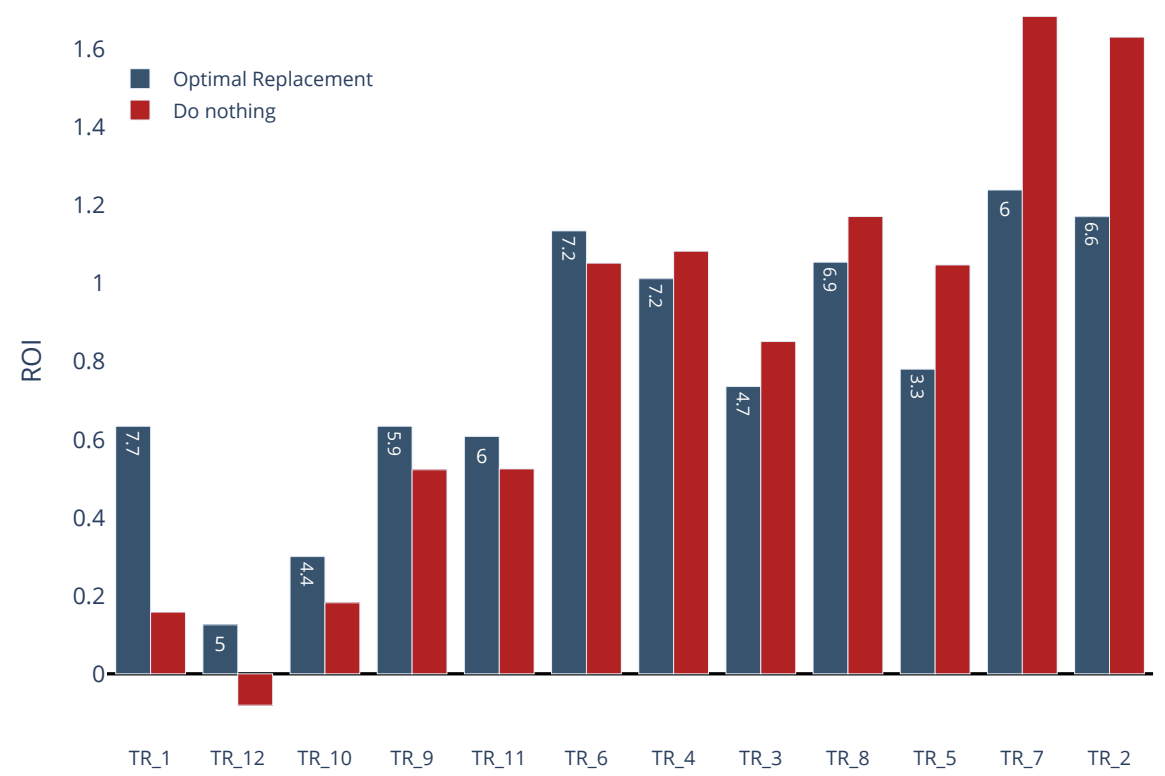

Figure 13. Ranking by higher benefit of optimal asset fleet replacement. 
To illustrate the influence of replacement on $R O I$, Figure 14 shows the $R O I$ for the decision with the highest benefit (TR_1) considering different replacement times. Here, it can be appreciated how an early or late replacement significantly impacts the return of investment. The point at time 35 refers to the decision to do nothing.

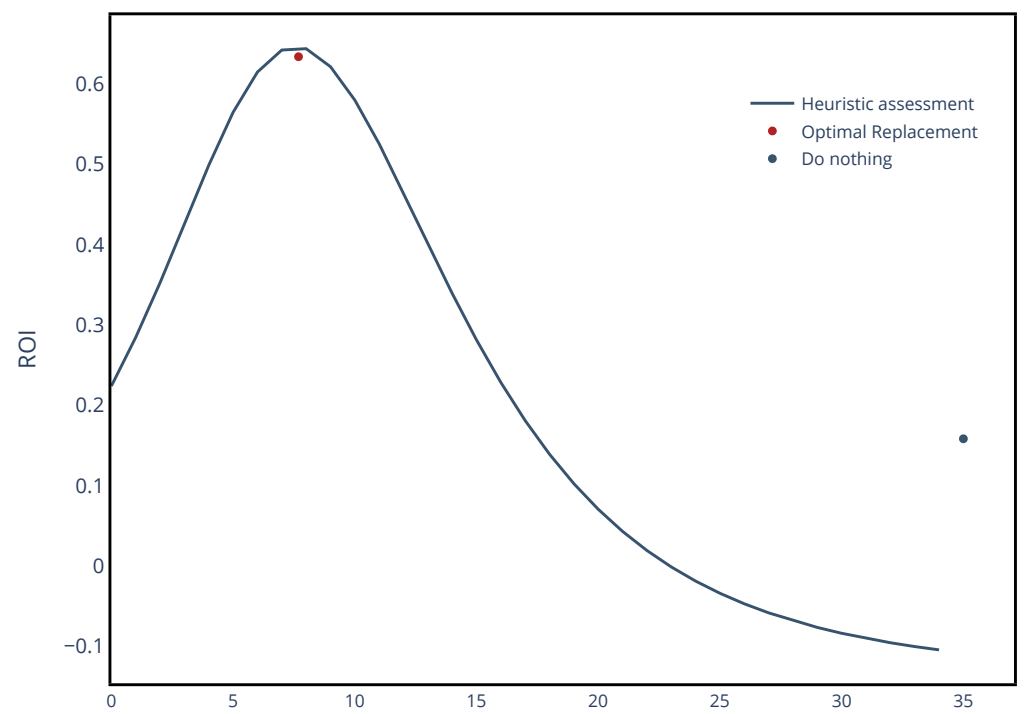

Figure 14. ROI for TR_1 considering different replacement times.

The influence of replacing TR_1 on the failure rate and POF is shown in Figure 15. Here, it can be appreciated that when the asset is replaced at time 7.7 , approximately in the year 2029, the failure rate comes to $\lambda_{0}$, and the growth of both cumulative failure rate and POF decreases compared with the do noting decision.
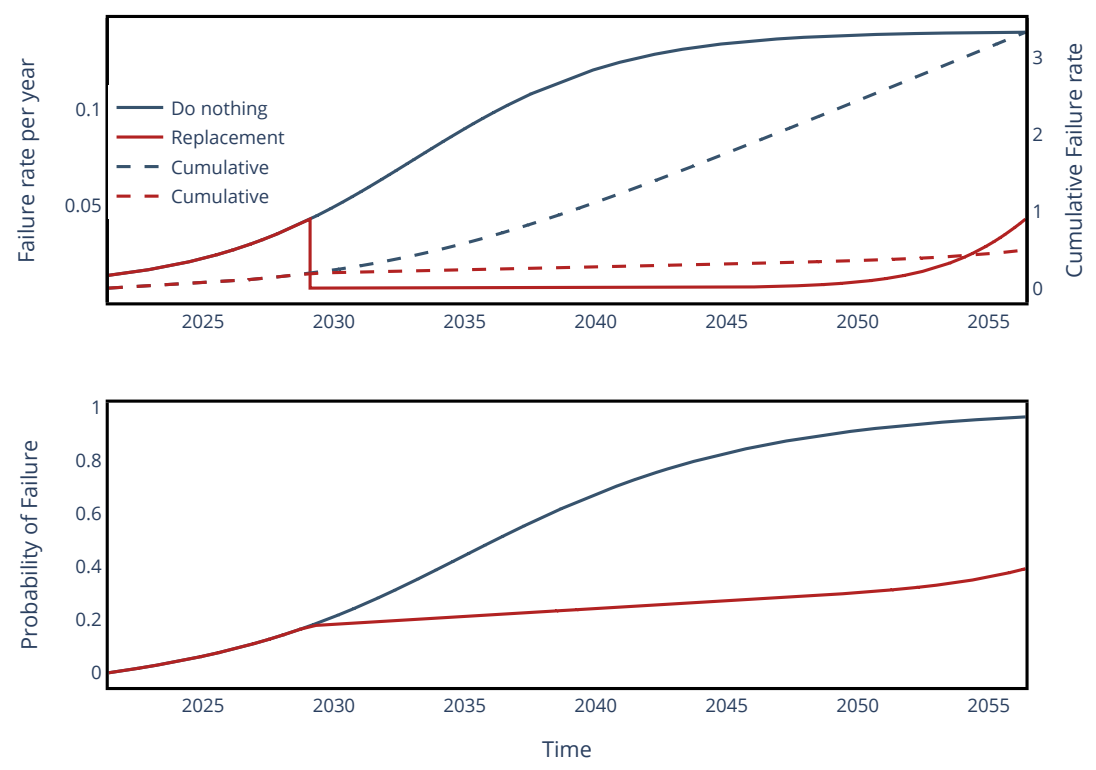

Figure 15. Influence of the optimal TR_1 replacement on their failure rate and POF.

\subsubsection{Optimal Maintenance}

In order to enhance the decision-making process, an optimal maintenance strategy must be estimated. In this paper, the strategy considers a constant frequency of maintenance seeking to obtain the maximum ROI at the end of life of the asset. In this case, for the assessment, a strategy by which the health index is held below 0.2 after each major maintenance is assumed. In other words, the maintenance has a direct impact on the HI. 
In Figure 16, the comparison between replacement and maintenance strategies under the assumed conditions is shown, where bar numbers mean the optimal replacement time and frequency of maintenance, respectively. Here it can be appreciated that the optimal decision for TR_1 is replacing the asset in the year 7.7 instead of performing maintenance every 4 years. For the rest of the assets, a higher ROI is obtained with maintenance instead of replacing. It is worth emphasizing that the transformer with the lowest maintenance interval is the TR_12, which is a consequence of its poor condition and high failure impact.

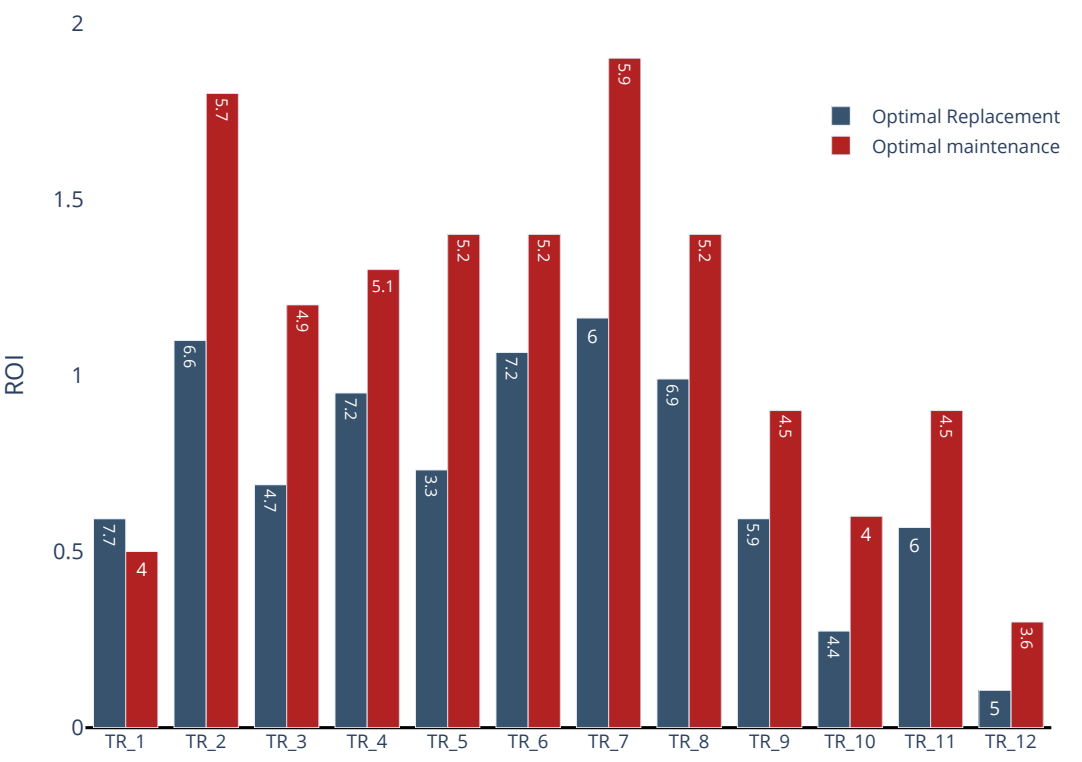

Figure 16. Comparison between ROIs obtained to employ an optimal replacement and a maintenance strategy for the entire asset fleet.

To illustrate the influence of maintenance over the assets, Figure 17 shows the failure rate behavior for TR_1, employing the estimated optimal maintenance frequency: in this case, approximately every 4 years. By doing maintenance, the POF is reduced to less than $40 \%$ compared to almost $100 \%$ if doing nothing. Figure 18 shows the influence of using different maintenance frequencies on ROI and the optimal frequency estimated using the proposed methodology. The slopes in the plot are the result of the integer value of the number of maintenance instances.
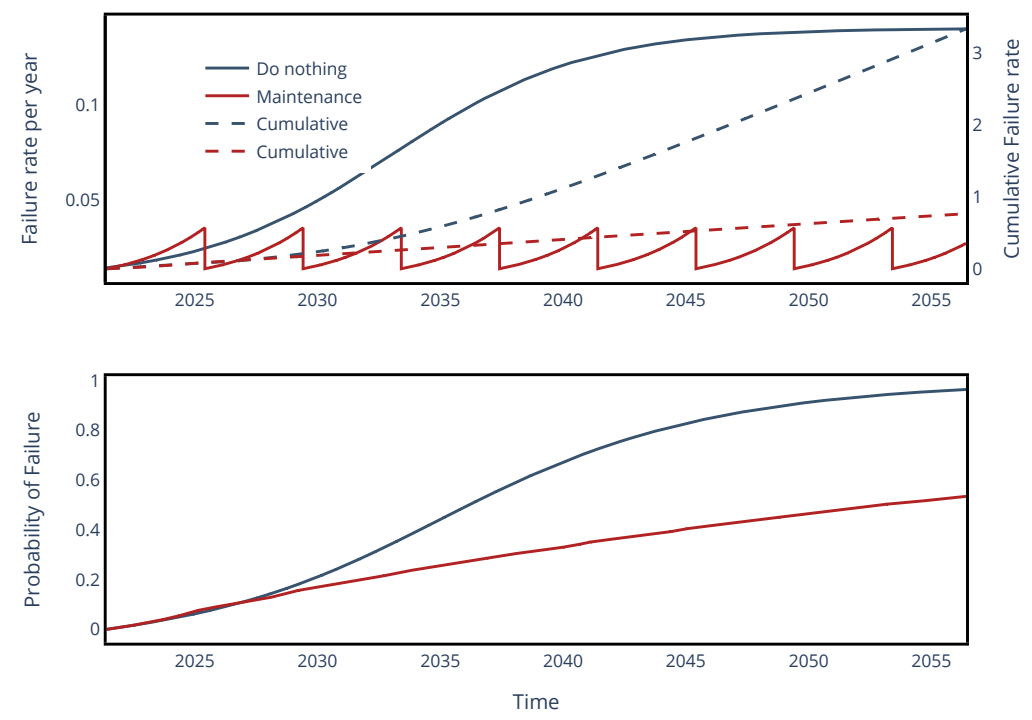

Figure 17. Influence of the optimal TR_1 maintenance strategy on its failure rate and POF. 


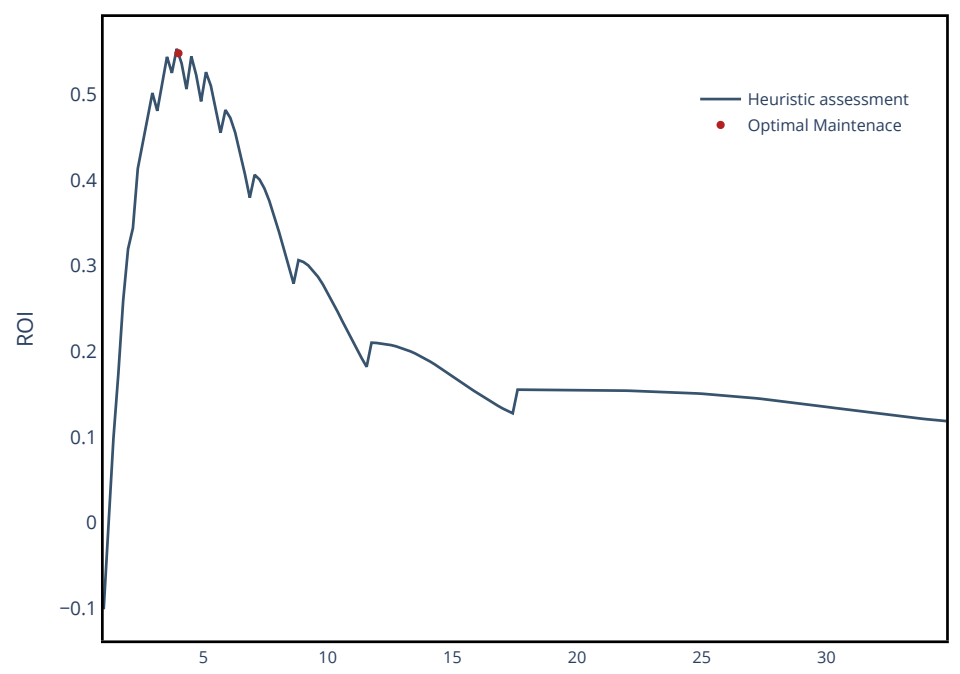

Figure 18. ROI for TR_1 considering different maintenance frequencies.

\subsection{Discussion of Results}

The implementation of the proposed methodology for supporting decision making by prioritizing ranking was supported by the definition of replacement times and maintenance strategy for a transformer fleet. The ranking was computed to optimize the ROI, solving the proposed problem formulation. This optimization considers a monetized risk increasing in time. Considering risk forecasting using the condition records as well as critically in a novel optimization formulation was the main contribution of this paper. This methodology was assessed considering common power transformer condition records and common strategic objectives by computing the criticality.

\section{Conclusions}

As the main contribution of this paper, a novel methodology for decision making based on optimal return on investment considering a holistic view was proposed. As part of the methodology, a mathematical formulation to optimize the ROI for decision making was developed in order to determine the replacement times and maintenance periods. This methodology can be used to support decision making in electrical systems using the risk index to optimize the return on investment. The risk assessment is based on the cost of decisions and their impact on the risk. We employed a monetized criterion of the RI using the penalties when the strategic objectives are impacted. The strategic objectives assessed were financial, reliability-related, environmental, and legal; however, according to the organization context and stakeholder expectations, objectives such as safety, reputation, and compliance, among others, can be considered. In this way, it would be possible to evaluate the cost of decisions such as repairs, refurbishment, replacement of the asset, or doing nothing. This methodology seeks to estimate the risk index through the use of a historical diagnostics test estimating the asset health condition. To summarize, the asset manager can use the findings in this paper to improve replacement and maintenance strategies considering a holistic view seeking to obtain the value of the assets. However, the internal financial issues must be considered, and the relationship between the HI and the failure rate must be fitted using records of failures. This fit can be performed, for example, by using Bayesian statistics.

As future research, in order to improve the risk forecasting, alternative methods to predict the asset condition could be employed. The methodology proposed in this work was implemented for power transformers in an open source tool. The library is open to including, in future research, other types of assets into the portfolio fleet such as lines, circuit breakers, etc., as well as other technologies such as dynamic ratings to support decision making. 
Author Contributions: Conceptualization, D.L.A., D.F.R., A.C. and S.R.; methodology, D.L.A., D.F.R., A.C., F.F.d.S., C.L.B. and S.R.; validation, D.L.A. and A.C.; formal analysis, D.L.A., D.F.R., A.C., F.F.d.S., C.L.B., R.G. and S.R.; investigation, D.L.A., D.F.R., A.C., F.F.d.S., C.L.B. and S.R.; writing, review and editing, D.L.A., D.F.R., A.C., F.F.d.S., C.L.B. and S.R.; funding acquisition and supervision, A.C. and S.R. All authors have read and agreed to the published version of the manuscript.

Funding: This research was supported in part by the "Ministère des Relations internationales et de la Francophonie-MRIFQ" and the "Fondo Nacional para el Financiamiento de la Ciencia, la Tecnología y la Innovación-FRANCISCO JOSE DE CALDAS-MINCIENCIAS" under award 811 of 2018.

Conflicts of Interest: The authors declare no conflict of interest.

\section{References}

1. CIGRE WG C1.25. Asset Management Decision Making Using Different Risk Assessment Methodologies; CIGRE: Boston, MA, USA, 2013.

2. CIGRE WG C1.34. TB 787: ISO Series 55000 Standards: Implementation and Information Guidelines for Utilities; CIGRE: Boston, MA, USA, 2019; pp. 1-203.

3. Maletič, D.; Maletič, M.; Al-Najjar, B.; Gomišček, B. An Analysis of Physical Asset Management Core Practices and Their Influence on Operational Performance. Sustainability 2020, 12, 9097. [CrossRef]

4. Lima, E.S.; McMahon, P.; Costa, A.P.C.S. Establishing the relationship between asset management and business performance. Int J. Prod. Econ. 2021, 232, 107937. [CrossRef]

5. Abu-Elanien, A.E.; Salama, M.M. Asset management techniques for transformers. Electr. Power Syst. Res. 2010, 80, 456-464. [CrossRef]

6. IEC. Strategic asset management of power networks. In International Electrotechnical Commission; IEC: New York, NY, USA, 2015.

7. Goyal, A.; Aprilia, E.; Janssen, G.; Kim, Y.; Kumar, T.; Mueller, R.; Phan, D.; Raman, A.; Schuddebeurs, J.; Xiong, J.; et al. Asset health management using predictive and prescriptive analytics for the electric power grid. IBM J. Res. Dev. 2016, 60, 4:1-4:14. [CrossRef]

8. Bertling, L.; Allan, R.; Eriksson, R. A Reliability-Centered Asset Maintenance Method for Assessing the Impact of Maintenance in Power Distribution Systems. IEEE Trans. Power Syst. 2005, 20, 75-82. [CrossRef]

9. Koksal, A.; Ozdemir, A. Improved transformer maintenance plan for reliability centred asset management of power transmission system. IET Gener. Transm. Distrib. 2016, 10, 1976-1983. [CrossRef]

10. Dong, M.; Zheng, H.; Zhang, Y.; Shi, K.; Yao, S.; Kou, X.; Ding, G.; Guo, L. A Novel Maintenance Decision Making Model of Power Transformers Based on Reliability and Economy Assessment. IEEE Access 2019, 7, 28778-28790. [CrossRef]

11. Nagata, M.; Takehara, A.; Kurihara, I. Development of a support tool to level transmission equipment replacements over long term. In Proceedings of the 2009 IEEE/PES Power Systems Conference and Exposition, Seattle, DC, USA, 15-18 March 2009; pp. 1-7. [CrossRef]

12. Fattaheian-Dehkordi, S.; Fotuhi-Firuzabad, M.; Ghorani, R. Transmission System Critical Component Identification Considering Full Substations Configuration and Protection Systems. IEEE Trans. Power Syst. 2018, 33, 5365-5373. [CrossRef]

13. Ofgem. DNO Common Network Asset Indices Methodology; Technical Report January; Ofgem: London, UK, 2017.

14. Côté, A.; Messaoudi, D.; Komljenovic, D.; Alarie, S.; Blancke, O.; Boudreau, J.; Gaha, M.; Truchon, E.; Pelletier, S. Development of an Asset Management Decision Support Tool for Hydro-Québec TransÉnergie. In Proceedings of the 2019 CIGRE CANADA Conference, Le Westin Montréal, QC, Canada, 16-19 September 2019.

15. Komljenovic, D.; Messaoudi, D.; Côté, A.; Gaha, M.; Vouligny, L.; Alarie, S.; Dems, A.; Blancke, O. Asset Management in Electrical Utilities in the Context of Business and Operational Complexity. In 14th WCEAM Proceedings; Crespo Márquez, A., Komljenovic, D., Amadi-Echendu, J., Eds.; Springer International Publishing: Cham, Switzerland, 2021; pp. 34-45. [CrossRef]

16. CIGRE WG C1.38. Valuation as a Comprehensive Emerging Developments Management in View of Approach to Asset-TB 791; Number September; CIGRE: Boston, MA, USA, 2019; pp. 1-45.

17. Alvarez, D.L.; Rosero, L.S.; Rivera, S.R.; Romero, A.A. A Framework For Asset Management in Electrical Systems, Part I: Conceptual Model. In Proceedings of the 2019 IEEE Workshop on Power Electronics and Power Quality Applications (PEPQA), Manizales, Colombia, 30-31 May 2019; pp. 1-6. [CrossRef]

18. Azmi, A.; Jasni, J.; Azis, N.; Kadir, M.A. Evolution of transformer health index in the form of mathematical equation. Renew. Sustain. Energy Rev. 2017, 76, 687-700. [CrossRef]

19. CIGRE WG C1.16. Transmission Asset Risk Management; Technical Brochure 422; CIGRE: Boston, MA, USA, 2010.

20. Brown, R.E.; Frimpong, G.; Willis, H.L. Failure rate modeling using equipment inspection data. IEEE Trans. Power Syst. 2004, 19, 782-787. [CrossRef]

21. Athay, T.; Podmore, R.; Virmani, S. A Practical Method for the Direct Analysis of Transient Stability. IEEE Trans. Power Appar. Syst. 1979, PAS-98, 573-584. [CrossRef]

22. Cruz, L.M.; Alvarez, D.L.; Rivera, S.R.; Herrera, F.A. On-Line Contingency Assessment Using Short-Term Load Forecasting. In Proceedings of the 2019 FISE-IEEE/CIGRE Conference-Living the Energy Transition (FISE/CIGRE), Medellin, Colombia, 4-6 December 2019; pp. 1-6. [CrossRef] 
23. Cruz, L.M.; Alvarez, D.L.; Rivera, S.R.; Herrera, F.A. Short-Term Demand Forecast Using Fourier Series. In Proceedings of the 2019 IEEE Workshop on Power Electronics and Power Quality Applications (PEPQA), Manizales, Colombia, 30-31 May 2019; pp. 1-5. [CrossRef]

24. Thurner, L.; Scheidler, A.; Schafer, F.; Menke, J.H.; Dollichon, J.; Meier, F.; Meinecke, S.; Braun, M. Pandapower-An Open-Source Python Tool for Convenient Modeling, Analysis, and Optimization of Electric Power Systems. IEEE Trans. Power Syst. 2018, 33, 6510-6521. [CrossRef]

25. IEEE. Guide for the Interpretation of Gases Generated in Oil-Immersed Transformers; IEEE: New York, NY, USA, 2009. [CrossRef]

26. IEEE. IEEE Guide for Diagnostic Field Testing of Fluid-Filled Power Transformers, Regulators, and Reactors; IEEE: New York, NY, USA, 2013; Volume 2013, pp. 1-121. [CrossRef]

27. Rosero, L.S.; Alvarez, D.L.; Amortegui, F.J.; Hernandez, G.; Garcia, S.R. A Framework For Asset Management in Electrical Systems, Part II: Case Study-Power Transformers. In Proceedings of the 2019 IEEE Workshop on Power Electronics and Power Quality Applications (PEPQA), Manizales, Colombia, 30-31 May 2019; pp. 1-6. [CrossRef]

28. Virtanen, P.; Gommers, R.; Oliphant, T.E.; Haberland, M.; Reddy, T.; Cournapeau, D.; Burovski, E.; Peterson, P.; Weckesser, W.; Bright, J.; et al. SciPy 1.0: Fundamental algorithms for scientific computing in Python. Nat. Methods 2020, 17, 261-272. [CrossRef] [PubMed] 